\title{
CATALYTIC DEGRADATION OF LINEAR LOW-DENSITY POLYETHYLENE OVER HY-ZEOLITE VIA PRE- DEGRADATION METHOD
}

\author{
Ishaka Muhammad ${ }^{1}$, Nura Makwashi ${ }^{2}$, George Manos ${ }^{1}$ \\ ${ }^{1}$ Chemical Engineering, University College London, Torrington Place, London WC1E 7JE, UK \\ ${ }^{2}$ Division of Chemical and Petroleum Engineering, London South Bank University, SE1 OAA \\ Corresponding Author: g.manos@ucl.ac.uk,+44 2073832348.
}

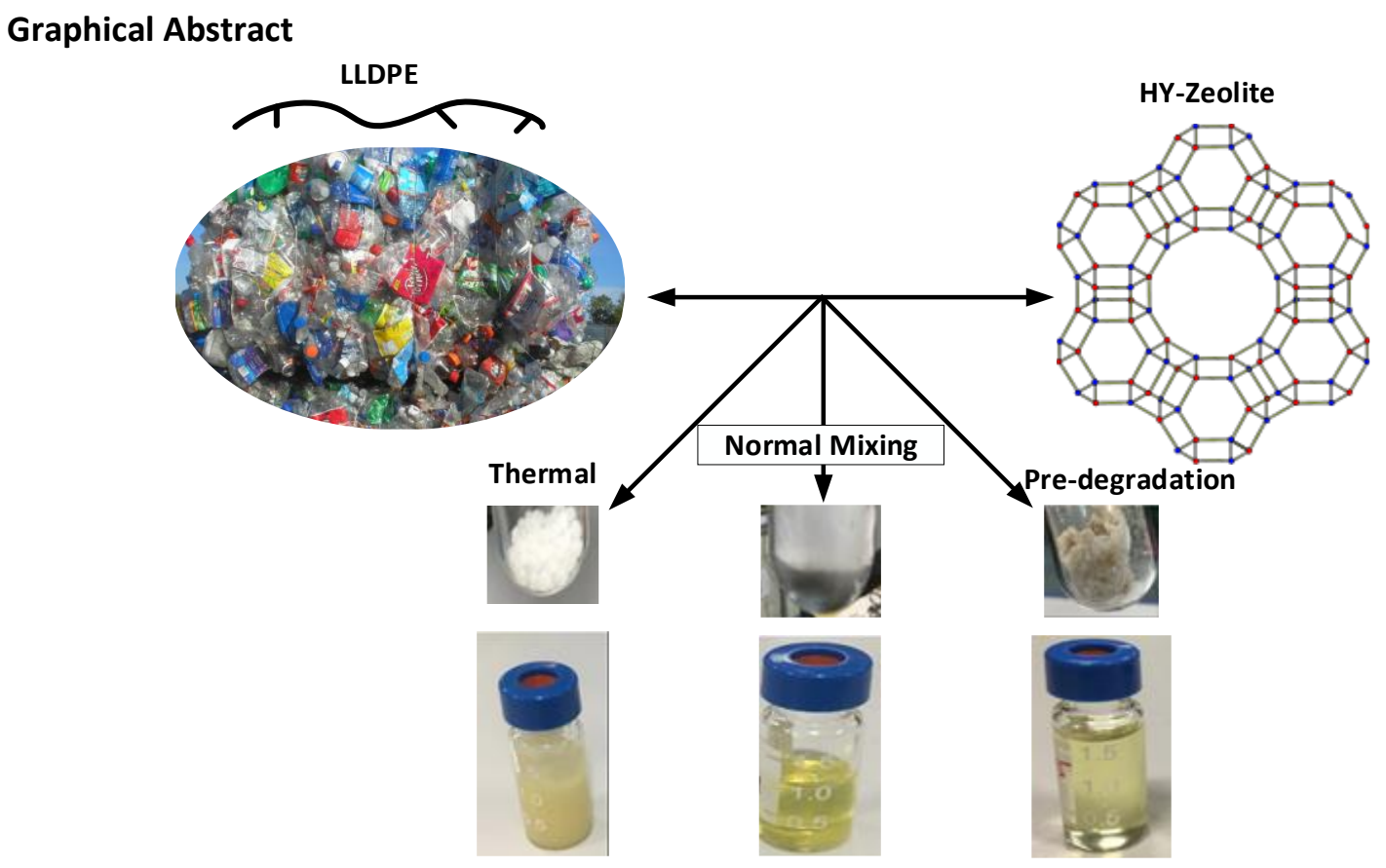

\section{Abstract}

The catalytic degradation of linear low-density (IIPE) polyethylene over HY-zeolite catalyst was studied in a semi-batch reactor. One of the important problems encountered during catalytic pyrolysis of macromolecules is the contact with the catalyst, which is known to affect the product distribution and the quality of the coke formed. A pre-degradation procedure was introduced to achieve efficient contact between the LLDPE macromolecules and the catalyst. The influence of the pre-degradation to the reaction conditions including holding time, temperature, polymer to catalyst ratio and flow rate of carrier gas was examined. Moreover, the pre-degradation results were compared with the results obtained using normal mixing procedure. The results obtained showed that, pre-degradation promotes the liquid fraction by a factor of more than one-fold increase at the expense of the gas fraction and the coke yield. The optimal liquid fraction with pre-degradation was obtained at low reaction temperature and catalyst amount respectively, i.e. high polymer to catalyst ratio, making it economically viable method for the degradation of IldPE. 
The coke content was analysed using TGA in nitrogen atmosphere to remove the soft coke and then in air isothermally at the final temperature to burn the hard coke. The TGA results of the coked sample show less concentration of coke components on the catalyst using the pre-degradation method as compared to the normal mixing which shows high concentration of coke components especially at low reaction temperature. Moreover, the majority of the coke components produced using the pre-degradation method were soft coke, making it more efficient for the re-usability of the catalyst.

The liquid samples collected were analysed using gas chromatography and the products distribution were presented in the form of boiling point distribution curves. The bulk of the liquid products produced were lighter fractions with a peak around the gasoline range.

Key words: Catalytic pyrolysis; pre-degradation; HY-zeolite; IIdPE; GC analysis; Coke characterisation

\section{Highlights}

- Polymer pre-degradation improves the efficiency of IldPE catalytic pyrolysis

- Pre-degradation improves the contact between IIdPE and catalyst

- Pre-degradation increases the quantity and quality of the liquid fractions

- Pre-degradation decreases the quantity of the coke yield

- Pre-degradation increases the volatility of the soft coke

\section{Introduction}

Plastics have played a fundamental contribution to our society. They are widely used in the daily life applications such as packaging goods, containers, toy industry, electronic industry, etc. Plastic production has increased drastically generating a huge amount of plastic waste, which serve as a serious environmental concern [1]. About half of the overall plastic production consists of polyolefins which include linear low density polyethylene (IIdPE), low density polyethylene (IdPE), high density polyethylene (hdPE), and polypropylene (PP) [2]. Among the different types of polyolefins, IIdPE has seen the fastest growth rate in usage and comprises of approximately $25 \%$ of the annual polyethylene production around the world, approaching 13 million metric tons. IIPE is made by the copolymerization of ethylene and $\alpha$-olefins with a narrower molecular weight distribution and short-chain branching. It can be represented by the general 
formula $-\mathrm{CH}_{2}-\mathrm{CH}_{2}-\mathrm{CH}_{2}-\mathrm{CH}-\left(\mathrm{C}_{\mathrm{n}-2} \mathrm{H}_{2(\mathrm{n}-2)+1}\right)$ where $\mathrm{n}$ is the number of carbon atoms in the $\alpha$-olefin. The most commonly used $\alpha$-olefins are 1-butene, 1-hexene, 4-methyl-1-pentene, and 1-octene [3].

In recent years, there is a significant increase in the production, consumption and the disposal of plastic products. In Europe for instance, in 2015, 49 million tonnes of plastic have been produced with 25.8 million tonnes of post-consumer plastics waste ended up in waste streams from which $69.2 \%$ was recovered through recycling and energy recovery processes while $30.8 \%$ went to landfill [4]. In 2016, only a year later, the European plastics demand has increased to 49.9 million tonnes with 27.1 million tonnes collected as plastic post-consumer waste from which $72.7 \%$ was recovered through recycling and energy recovery processes while $27.3 \%$ went to landfill [5].

The municipal solid waste contains plastics, which consist of mainly high-density polyethylene (hdPE), linear low-density polyethylene (IIdPE), low-density polyethylene (IdPE), polypropylene (PP), and polystyrene (PS), polyvinyl chloride (PVC), and polyethylene terephthalate (PET) [6]. More than $40 \%$ of the municipal waste stream comprises of paper and plastic [7].

In order to reduce the adverse effects brought by plastic waste, efforts have been made in promoting recovery of plastic waste for recycling [6], [8], [9]. From $2006-2016$, the total plastic waste generated in Europe has increased by $11 \%$ whose recycling increased by $79 \%$ while the landfill has decreased by $43 \%$ [5]. Plastic waste presents a cheap source of raw materials encouraging its recycling which has become a necessity. Among all the methods of recycling plastic waste, only chemical recycling conforms to the principles of sustainable development as it leads to the formation of raw materials from which the plastics are originally made saving natural mresources while it has the highest potential for a successful future commercialization [2], [5], [9], [10], [11]. Chemical recycling may contribute significantly towards a solution to the energy crisis [9], [12]. It utilises both the thermal and/or catalytic degradation [13], [14]. Pure thermal degradation of plastic waste requires high temperatures and produces heavy products that need further processing [2], [10], [11], [15]. The presence of catalyst reduces the process temperature as it lowers the activation energy for breaking $\mathrm{C}-\mathrm{C}$ bonds and decreases the residence time of plastics in the reactor, because of the faster rate of degradation. It also produces hydrocarbon in the motor fuel range, which eliminates the need for further upgrading process steps [2], [10], [11], [15], [16], [17], [18],[19].

Liquid fuel has been regarded as the most valuable product from the thermal and catalytic degradation of plastic. Gaseous products are considered of low value but they are useful as well, as their 
burning can contribute to the energy demand. However, excess gas production is not desirable because of their transportation costs. Consequently, the target of a commercially viable recycling process should be an increase of the liquid product yield [2], [19], [20].

Different types of reactors have been evolved in the literature of plastic pyrolysis with the aim to maximize the liquid yield and to adopt a very wide possibility of feedstock handling. Due to their low thermal conductivity, plastic pyrolysis experienced a low and irregular heating pattern in the reaction environment [21]. Continuous catalytic cracking of polyolefins has been associated with fused-plastic of sticky nature that clogs the reactor with the formation of severe by-products [22]. Inadequate reactor design leads to undesired reaction conditions with detrimental effect on the product quality [21]. In order to overcome these problems, several reactors design have been studied from lab to pilot plant scale reactors with several improvements to attain specific objectives [22]. Stirred reactors have been proposed as a simpler alternative to improve the heat supply to the plastic and to minimize heat transfer limitations [21], [23], [24]. Reactors of different configurations have been reported.

Batch and semi-batch reactors have been used for thermal and catalytic pyrolysis of virgin and waste plastic, they have the advantage of simple design and easy to control process parameters [12], [23], [25]. Batch reactors require frequent materials charging and restarting of the process, which represent a drawback in the recycling industry for continuous application. It is more favourable to develop a continuous pyrolysis process, that does not require frequent materials charging and restarting that could be less labour-intensive. Few studies for polymer pyrolysis have been conducted using fixed bed reactors [26]. There are several reports regarding the combination of fixed bed reactor after thermal pyrolysis of polymer feed [12], [27], [28], [29]. Fixed bed reactors are considered very economical due to the manageable maintenance and operation of the unit. Their limitations arise from the limited surface area of the catalysts typically accessible by the reactants and the particle size and shape of the feedstock [30]. Following the development of the pyrolysis technology, there is a need to develop a more robust and continuous process for the polymer pyrolysis before it can be applied in scalable production in the industries [12]. Fluidized bed reactors, gained recent applications due to several advantages they possess, including excellent mixing properties, as well as improved heat transfer from the reactor to the polymer, compared to batch reactors [31], [32]. Fluidized beds are characterized by high solid mixing regime with a significant versatility on gas residence time giving them clear advantages over fixed beds [21], [30]. In Fluidized bed reactors, it is possible to periodically replace the used catalyst with the 
regenerated catalyst without halting the process. However, care has to be taken to avoid bed defluidization, as this can easily happen when melted plastic stick on the fluidized bed [12], [32], [33], [34].

In order to avoid fluidization caused by melted plastic in fluidized bed reactor, the use of Conical spouted bed reactor (CSBR) was proposed, as the vigorous contact between different phases and collision between particles reduced the chance of particle agglomeration in the bed materials [21], [30], [35]. Shorter residence time of polymer materials in CSBR help to avoid secondary reactions that leads to the formation of coke precursors [35], [36], [37].

Thermal pyrolysis of plastic in continuous CSBR at low, moderate and high temperature range showed higher selectivity to wax products [38], [39]. At a lower temperature, waxes rich in parrafins were produced and the olefins content increased with temperature [12], [38]. As CSBR pyrolysis produces more wax rather than liquid and gaseous products a second reactor can be added for further cracking of the waxes in order to improve the pyrolysis performance [12], [24].

Two-stage pyrolysis system can be designed by thermally cracking the plastic in the reactor at the bottom, and the vapour formed was then flown upwards and reacted with the catalyst on the fixed bed reactor [40]. This could avoid direct contact of the catalysts with melted plastic, which causes difficulties in catalyst recovery after pyrolysis process, and rapid deactivation of the catalyst [12].

Microwave-assisted pyrolysis is receiving increasing attention from researchers, due to the several advantages over the traditional pyrolysis such as faster heating rate and cost effectiveness [41], [42]. One distinctive feature in MAP is the application of microwave power on the polymer materials, which is converted into heat at a fast rate. It is possible to raise the reaction temperature up to $1000^{\circ} \mathrm{C}$ in a short period in MAP using microwave absorber [43].

The use of sub-critical water (CW) system and supercritical water system (SCW) was attempted in plastic pyrolysis [12]. Supercritical water behaves as solvent and catalyst simultaneously in the process. The small hydrocarbons molecules formed during polymer pyrolysis can easily disperse in SCW, hence, the chance of subsequent condensation and coke formation is reduced [12], [44], [45].

Non-conventional reactors have been proposed to ease the polymer handling and ensure uniform heat supply [21]. The use of plasma technology allows for reaching temperatures of up to $8000{ }^{\circ} \mathrm{C}$ with extremely high heating rates of $10^{6}{ }^{\circ} \mathrm{C} \mathrm{s}^{-1}$ [46], [47]. The main advantage of this type of reactor is for the gasification of plastic, which needs high temperature to achieve full tar cracking, and consequently high gas 
yields [48]. Stelmachowski (2014) [49] had proposed molten metal bath reactor for the pyrolysis of plastics. This type of a reactor allows direct contact between the polymer and the molten metal which improves heat transfer and avoids the use of any stirring mechanical device [49], [50].

Despite the challenges of working with semi-batch reactors, they have been used largely in the labscale applications due to their easy design and operation. They also enable to work with large samples and particle sizes closer to the conditions used in industrial applications. Some of the recent work with Semi-batch were reported in the following literature [11], [15], [16], [19], [20], [51], [52], [53], [54], [55].

Zeolite-based catalysts [10], [11], [15], [16], [20], [56], [57], [58], [59], [60], have been used in catalytic degradation of polymer, as well as silica-alumina [61], clay-based catalysts [2], [15] and MCM-type mesoporous materials [62], [63]. The required properties of highly active catalysts for the pyrolysis of plastics are a large external surface area, bent and large pores for suppressing carbon deposits and rapid mass transfer of reactants and products. Many researchers have used various zeolites due to their acidity. The application of zeolites to the pyrolysis of waste plastics, however, has encountered technical problems, such as relatively high quantity of gas products and coke formation, which consequently decrease the liquid product yield. This is attributed to the very strong acidity of the zeolitic sites, which brings about severe cracking of the plastic molecules [16], [64], [65].

Different parameters, such as temperature, heating rate, and residence time and catalyst to polymer ratio as well as their contact have significant influence on the product yields of the catalytic pyrolysis process. The prominent among them that has attracted less attention is the contact between the polymer and the catalyst, which is known to directly or indirectly affect other factors. In this study, a novel pre-degradation procedure was introduced as a pre-treatment process to provide optimal contact between polymer and catalyst.

\section{Experimental}




\subsection{Materials}

The polymer feed is linear low-density polyethylene (IldPE) in pellet form provided by Vantage Polymers Ltd. It has an average particle size $1-2 \mathrm{~mm}$ with a density of $0.928 \mathrm{~g} / \mathrm{cm}^{3}$ and an average molar mass of $117 \mathrm{~kg} / \mathrm{mol}$. The HY zeolite catalyst was in powder form provided by Grace Gmbh. It has an average particle size of $1 \mu \mathrm{m}$ with a Si/Al ratio of 2.5 . The micropore area was $532.4 \mathrm{~m}^{2} / \mathrm{g}$, and the micropore volume was $0.26 \mathrm{~cm}^{3} / \mathrm{g}$. BET surface area was $590 \pm 23.5 \mathrm{~m}^{2} / \mathrm{g}$. Although we have not measured the catalyst acidity, the correlation between zeolite acidity and Si/Al ratio is well documented.

\subsection{Experimental setup: equipment}

The polymer pyrolysis experimental rig shown in Fig. 1 consists of a semi-batch pyrex reactor with two semicircle infrared heating elements for fast heating connected to a temperature controller, mass flow controller and two condensers placed in ice baths for liquid collection. The semi-batch pyrex reactor has an internal diameter of $30 \mathrm{~mm}$. The external diameter of the reactor was $35 \mathrm{~mm}$ and a total height of $150 \mathrm{~mm}$, with a capacity of $0.2 \mathrm{~L}$. At the beginning of the experiment, the catalyst sample was dried under a nitrogen stream at $473 \mathrm{~K}$ for $30 \mathrm{~min}$. Before the actual experiment, the reactor was purged with $100 \mathrm{~mL} / \mathrm{min}$ of nitrogen for 15 min, determined by a mass flow controller in order to remove any oxygen from the reactor. The liquid samples were collected in the condensers. The gases including the hydrocarbon products were collected in gas bags and disposed of safely. For each experimental run, the reactor and furnace temperatures were measured and recorded by a thermocouple each. The initial amount of IldPE was in all experiments equal to $2 \mathrm{~g}$. The polymer to catalyst ratio was varied, by varying the amount of catalyst. The experiment was usually run for 30 $\min$. At the end of each experiment, the condensers were weighed to calculate the mass of the liquid collected and the reactor was cooled and weighed to determine the mass of the converted plastic. At the end of the experiment, the majority of the plastic had been converted to gases and liquids, leaving in the reactor only catalyst with deposited coke and any unvolitilised solid polymer remnants. The latter were identified visually. In only two catalytic pyrolysis experiments polymer remnants were identified for which the amount of coke includes their amount too as it is not possible to separate them from the catalyst particles. In pure thermal experiments in the absence of catalysts all the amount left in the reactor was unvolitilided polymer. 


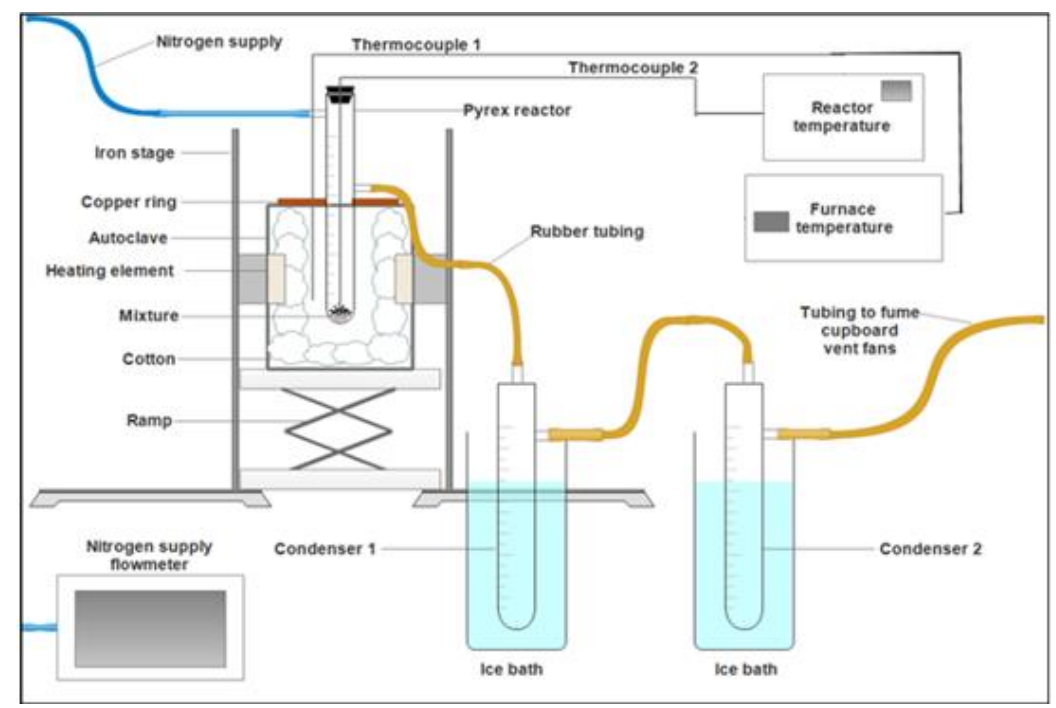

Figure 1. Schematic diagram of the laboratory semi-batch reactor system

\subsection{Experimental Calculations}

The conversion to volatile products, liquids and gases, was calculated as the fraction of the initial mass of IldPE reacted to form the volatile products. The yield to the liquid products was calculated as the mass of the liquid collected divided by the initial amount of the IIdPE and represents the fraction of the original IIdPE converted to the liquid products. The coke concentration was estimated by TGA and converted to yield based on the catalyst amount in the reactor.

Coke concentration is the amount of coke deposited on the catalyst divided by the catalyst mass and represents the amount of coke formed per g of catalyst: $\quad C_{c}=m_{c} / m_{\text {cat }}$

Coke yield is the mass of the coke divided by the initial amount of the IIdPE and represents the fraction of the original IldPE converted to coke:

$$
Y_{c}=m_{c} / m_{p 0}
$$

As explained in section 2.1 above, in two catalytic pyrolysis experiments, the coke amount included the unvolatilised polymer remnants. These are the $623 \mathrm{~K}$ experiments at 3:1 and 4:1 polymer to catalyst ratios in Table 2.

\subsection{Liquid sample analysis}

The liquid products were analysed on a Shimadzu 2014 gas chromatograph equipped with a flame ionization detector (FID) using a non-polar Rtx-1 DHA $100 \mathrm{~m} \times 0.25 \mathrm{~mm} \times 0.50 \mu \mathrm{m}$ capillary column. The hydrogen flow was adjusted to $30 \mathrm{~mL} / \mathrm{min}$, and the injector temperature was set at $270^{\circ} \mathrm{C}$. The temperature program began with a hold at $40{ }^{\circ} \mathrm{C}$ for $10 \mathrm{~min}$ followed by a ramp of $5{ }^{\circ} \mathrm{C} / \mathrm{min}$ to $270{ }^{\circ} \mathrm{C}$, and a hold for another $30 \mathrm{~min}$. The temperature of FID detector was fixed at $300^{\circ} \mathrm{C}$. Injections of $1 \mu \mathrm{l}$ and $0.2 \mu \mathrm{L}$ were used for the calibrations 
standard and the oil samples respectively. Splitless ratio was used for the standard and 50:1 for the oil samples. For the samples from the thermal pyrolysis, the method has been reviewed with additional heating step. A ramp from $270{ }^{\circ} \mathrm{C}$ to $300{ }^{\circ} \mathrm{C}$ and hold for $50 \mathrm{~min}$. The maximum injector temperature of $300{ }^{\circ} \mathrm{C}$ was used because the maximum column temperature was $340{ }^{\circ} \mathrm{C}$ and the temperature of FID detector was fixed at $320^{\circ} \mathrm{C}$. After several test run, the method used for the lighter oil samples was found to be good as no any peak appeared at around $86 \mathrm{~min}$. For the oil samples from the thermal pyrolysis, which are heavier, $142 \mathrm{~min}$ was found enough with the temperature ramp to $300^{\circ} \mathrm{C}$. A calibration mixture of normal alkanes $C_{5}-C_{20}$ (standard) was run at the beginning of the analysis to assign retention time to each components. The whole sample for analysis was divided into intervals between the boiling points of the normal alkanes of the calibration mixture, Table 1. The mass fraction corresponding to each interval was calculated from the sum of the area fractions of all components in this interval. The mass fraction of each component is set equal to the area fraction. To each interval, the probability density function value was then calculated, as being equal to the mass fraction of this interval divided by the temperature interval width $\Delta T$. Hence, the probability density function is expressed as $\% / K$. In the graphs of the boiling point distribution, each interval is represented by its middle value. All components with retention time smaller than that of $n$-pentane were assigned to a group corresponding to the boiling point interval between $\mathrm{n}$-butane and $\mathrm{n}$-pentane (272.70-309.20 K). This was repeated for all 16 groups and a total distribution curve for the overall sample was constructed as shown in the table1.

Table 1. Boiling Point Distribution Intervals

\begin{tabular}{llllll}
\hline $\begin{array}{l}\text { Group } \\
\text { carbon atom }\end{array}$ & $\begin{array}{l}\text { Boiling } \\
(\mathbf{K})\end{array}$ & $\begin{array}{l}\text { point } \\
\text { atom }\end{array}$ & $\begin{array}{l}\text { Group of carbon } \\
\text { average } \\
\text { Boiling } \\
(\mathbf{K})\end{array}$ & $\begin{array}{l}\Delta \mathbf{T}(\mathbf{K}) \\
\text { point }\end{array}$ & Retention time \\
\hline $\mathrm{C}_{4} \mathrm{H}_{10}$ & 272.70 & $\mathrm{C}_{4} \mathrm{H}_{10}-\mathrm{C}_{5} \mathrm{H}_{12}$ & 290.95 & 36.50 & - \\
$\mathrm{C}_{5} \mathrm{H}_{12}$ & 309.20 & $\mathrm{C}_{5} \mathrm{H}_{12}-\mathrm{C}_{6} \mathrm{H}_{14}$ & 325.55 & 32.70 & 16.03 \\
$\mathrm{C}_{6} \mathrm{H}_{14}$ & 341.90 & $\mathrm{C}_{6} \mathrm{H}_{14}-\mathrm{C}_{7} \mathrm{H}_{16}$ & 356.75 & 29.70 & 20.94 \\
$\mathrm{C}_{7} \mathrm{H}_{16}$ & 371.60 & $\mathrm{C}_{7} \mathrm{H}_{16}-\mathrm{C}_{8} \mathrm{H}_{18}$ & 385.20 & 27.20 & 27.16 \\
$\mathrm{C}_{8} \mathrm{H}_{18}$ & 398.80 & $\mathrm{C}_{8} \mathrm{H}_{18}-\mathrm{C}_{9} \mathrm{H}_{20}$ & 411.40 & 25.20 & 33.26 \\
$\mathrm{C}_{9} \mathrm{H}_{20}$ & 424.00 & $\mathrm{C}_{9} \mathrm{H}_{20}-\mathrm{C}_{10} \mathrm{H}_{22}$ & 435.65 & 23.30 & 38.64 \\
$\mathrm{C}_{10} \mathrm{H}_{22}$ & 447.30 & $\mathrm{C}_{10} \mathrm{H}_{22}-\mathrm{C}_{11} \mathrm{H}_{24}$ & 458.20 & 21.80 & 43.37 \\
$\mathrm{C}_{11} \mathrm{H}_{24}$ & 469.10 & $\mathrm{C}_{11} \mathrm{H}_{24}-\mathrm{C}_{12} \mathrm{H}_{26}$ & 479.30 & 20.40 & 47.61 \\
$\mathrm{C}_{12} \mathrm{H}_{26}$ & 489.50 & $\mathrm{C}_{12} \mathrm{H}_{26}-\mathrm{C}_{13} \mathrm{H}_{28}$ & 499.05 & 19.10 & 51.49 \\
$\mathrm{C}_{13} \mathrm{H}_{28}$ & 508.60 & $\mathrm{C}_{13} \mathrm{H}_{28}-\mathrm{C}_{14} \mathrm{H}_{30}$ & 517.65 & 18.10 & 55.05 \\
$\mathrm{C}_{14} \mathrm{H}_{30}$ & 526.70 & $\mathrm{C}_{14} \mathrm{H}_{30}-\mathrm{C}_{15} \mathrm{H}_{32}$ & 535.25 & 17.10 & 58.51
\end{tabular}




\begin{tabular}{llllll}
$\mathrm{C}_{15} \mathrm{H}_{32}$ & 543.80 & $\mathrm{C}_{15} \mathrm{H}_{32}-\mathrm{C}_{16} \mathrm{H}_{34}$ & 551.90 & 16.20 & 61.91 \\
$\mathrm{C}_{16} \mathrm{H}_{34}$ & 560.00 & $\mathrm{C}_{16} \mathrm{H}_{34}-\mathrm{C}_{17} \mathrm{H}_{36}$ & 567.60 & 15.20 & 65.26 \\
$\mathrm{C}_{17} \mathrm{H}_{36}$ & 575.20 & $\mathrm{C}_{17} \mathrm{H}_{36}-\mathrm{C}_{18} \mathrm{H}_{38}$ & 582.35 & 14.30 & 68.71 \\
$\mathrm{C}_{18} \mathrm{H}_{38}$ & 589.50 & $\mathrm{C}_{18} \mathrm{H}_{38}-\mathrm{C}_{19} \mathrm{H}_{40}$ & 596.30 & 13.60 & 72.43 \\
$\mathrm{C}_{19} \mathrm{H}_{40}$ & 603.10 & $\mathrm{C}_{19} \mathrm{H}_{40}-\mathrm{C}_{20} \mathrm{H}_{42}$ & 610.05 & 13.90 & 76.60 \\
$\mathrm{C}_{20} \mathrm{H}_{42}$ & 617.00 & $\mathrm{C}_{20} \mathrm{H}_{42}{ }^{+}$ & 617.00 & - & 81.45 \\
\hline
\end{tabular}

\subsection{Thermal gravimetric analysis}

For the TGA analysis of IIdPE with HY-catalyst (4:1) and coked HY-catalyst, ca.10 mg was heated to $473 \mathrm{~K}$ at a rate of $10 \mathrm{~K} / \mathrm{min}$ and was maintained for $30 \mathrm{~min}$ under nitrogen flow ( $30 \mathrm{mLN} / \mathrm{min}$ ) to remove the adsorbed water and any reaction mixture components. After this period, the temperature was raised to $1073 \mathrm{~K}$ at a rate of $5 \mathrm{~K} / \mathrm{min}$ and kept constant for $30 \mathrm{~min}$. The hard coke deposited on the catalyst was burnt out by switching from nitrogen to air at the final temperature $(1073 \mathrm{~K})$ at the same flow rate $(30 \mathrm{~mL} / \mathrm{min})$. For the IIdPE experiments, the sample was held at $873 \mathrm{~K}$ for $30 \mathrm{~min}$ to complete the degradation and then the temperature was ramped to $1073 \mathrm{~K}$ to remove the coke. The amount of soft coke in the catalyst would be equal to the difference between the sample mass after drying at $473 \mathrm{~K}$ and the sample mass at $1073 \mathrm{~K}$ i.e. before switching from nitrogen to air at the final temperature $1073 \mathrm{~K}$. The amount of hard coke is the mass difference of the sample mass before and after the switching from nitrogen to air, when the hard coke was completely burned. The concentration of the coke was estimated by dividing the corresponding coke amounts by the mass of the catalyst, which corresponds to the sample mass at the end of the TGA procedure after the burning of the coke.

\subsection{Coke Characterisation and Calculation}

The procedure used in this study as presented in Fig. 2 is simple, rapid and specific using Thermogravimetric analysis (TGA) of the coked catalyst. This method provides information about the character of coke components, more specifically their volatility. The procedure involved removal of water and reaction mixture from room temperature to $473 \mathrm{~K}$, which is represented by " $\mathrm{A}$ " in Fig. 2 . The Coke components can be classified into soft coke and hard coke. The soft coke is removed from $473 \mathrm{~K}$ to $873 \mathrm{~K}$ through volatilisation in inert nitrogen, which is represented by " $\mathrm{B}$ " in Fig. 2 . The hard coke remains on the catalyst even at high 
temperature $(873 \mathrm{~K})$ and is removed by burning i.e. by switching the atmosphere from nitrogen to air, which is represented by "C" in Fig. 2.

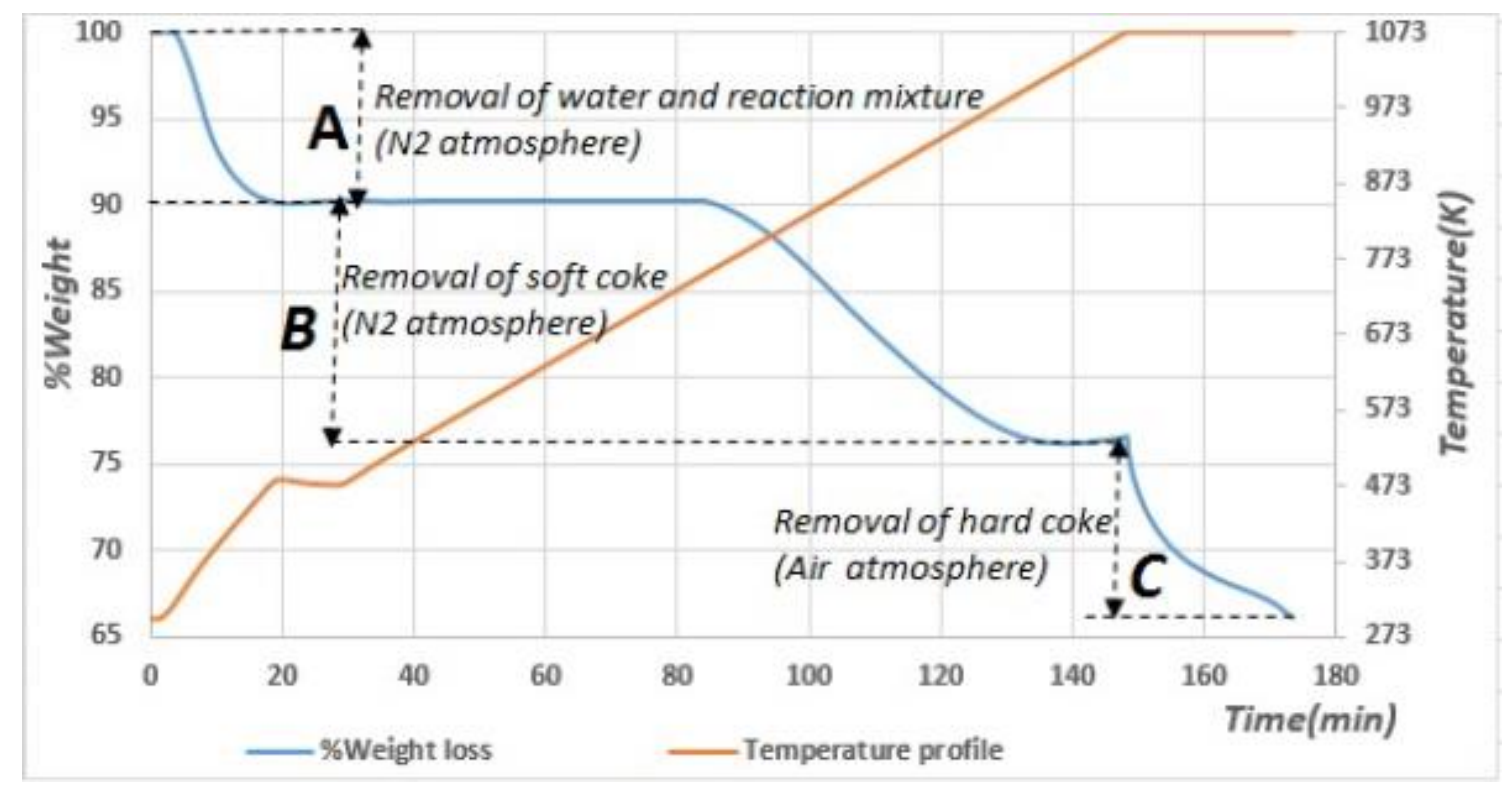

Figure 2: TGA of coked sample showing the coke characterisation

\subsection{Pre-degradation Procedure}

Pre-degradation is a pre-treatment method that involves heating the IldPE to a temperature around its melting point. In this study, $423 \mathrm{~K}$ and $453 \mathrm{~K}$ were used as the pre-degradation temperatures and was evaluated at different holding times i.e. 5, 10 and 15 min respectively. As the IIdPE has melted, the content is mixed constantly for about 1 min to produce intimate contact between the IIdPE and catalyst. There are no volatile products formed during pre-degradation. However, as shown by Manos et al. [11] there are changes taking place in the solid polymer structure in the form of shortening of the largest polymer chains.

\section{Results and discussion}

\subsection{The influence of pre- degradation on the rate and temperature of IIdPE degradation}

The effect of pre-degradation was evaluated using thermogravimetric analysis (TGA) method and the results are presented in Fig. 3. For the thermal degradation of IIdPE in the absence of catalyst, the degradation starts after b600 K with $10 \%$ degradation of IIdPE obtained at $704 \mathrm{~K}$.. For consistent comparison with other mixing methods, temperature at $10 \%$ conversion has been used as the initial degradation temperature. The degradation of IIdPE without catalyst was completed at $763 \mathrm{~K}$. For normal mixing, i.e. IldPE and catalyst being simply mixed thoroughly with spatula before the commencement of the experiment, the degradation started 
at $610 \mathrm{~K}$ and proceeded with higher rate up to $673 \mathrm{~K}$ with almost $40 \%$ conversion. After this temperature, the degradation continues slowly up to $745 \mathrm{~K}$ resulting into a shoulder with additional $20 \%$ conversion and the rest of the polymer is assumed to be converted via thermal cracking with a peak temperature at $761 \mathrm{~K}$ and additional $20 \%$ conversion was also obtained. With 5 min pre-degradation, the IIdPE degradation pattern has improved dramatically without any shoulder, attaining a maximum degradation temperature at $665 \mathrm{~K}$. To further explore the effect of the pre-degradation, the holding time was extended to 10 and 15 min respectively as shown in Fig. 3. For the 10 and 15 min pre-degradation holding time, the initial and maximum degradation temperatures were almost the same as the 5 min pre-degradation, but they showed higher conversion and low coke formation which is closely to $100 \%$ soft coke opposite to 5 min pre-degradation and normal mixing which delivered a lot of hard coke. The pre-degradation procedure was used for the thermal degradation, to find out if there is any thermal influence in the pre-degradation procedure or it is pure effect of intimate contact between the polymer and the catalyst. As indicated in Fig. 3, the effect of pre-degradation to the thermal degradation of IIdPE shifted towards higher temperature, an opposite trend to the catalytic degradation. Choi et al. [65] also reported thermal degradation of IIdPE with a maximum degradation temperature of $773 \mathrm{~K}$ which is similar to the result obtained by this study. For the catalytic degradation of IldPE, the presence of the short-branched chains on its skeleton suppresses the close contact with acid sites, resulting in a low conversion with normal mixing [66]. The bulky nature of the IIdPE molecules also affect the type of the catalyst-IIdPE contact. If the catalyst is not uniformly dispersed through the IIdPE, a mass transfer limitation could exist within the mixture, which are characteristic of heterogeneous catalysis [67]. For the normal mixing of IIdPE with the catalyst, the result suggests that, the available contact between the IIdPE and the catalyst permits the degradation of a fraction of the IIdPE at lower temperatures, through a catalytic pathway, whereas, the rest of the IIdPE were decomposed by thermal cracking at higher temperatures [67]. A limited number of studies have looked into the effect of the contact between the polymer and the catalyst. Sakata et al. [68] studied the effect of catalytic contact mode on the degradation of polypropylene. Their findings suggested that, the acid sites of the catalyst in contact with the polymer melt (liquid phase) accelerated the degradation of the polymer significantly into lower molecular weight compounds. Marcilla et al. [69] in their work on the polymer-catalyst contact effectiveness and heating rate influence on the HDPE pyrolysis showed that a good contact between polymer and catalyst accelerates the activity of the catalyst, reduces the heavy fractions and leads to higher volatile yields than thermal degradation. The finding and conclusions by these 
studies were some of the points highlighted by our study as the advantage of pre-degradation method over the normal mixing.

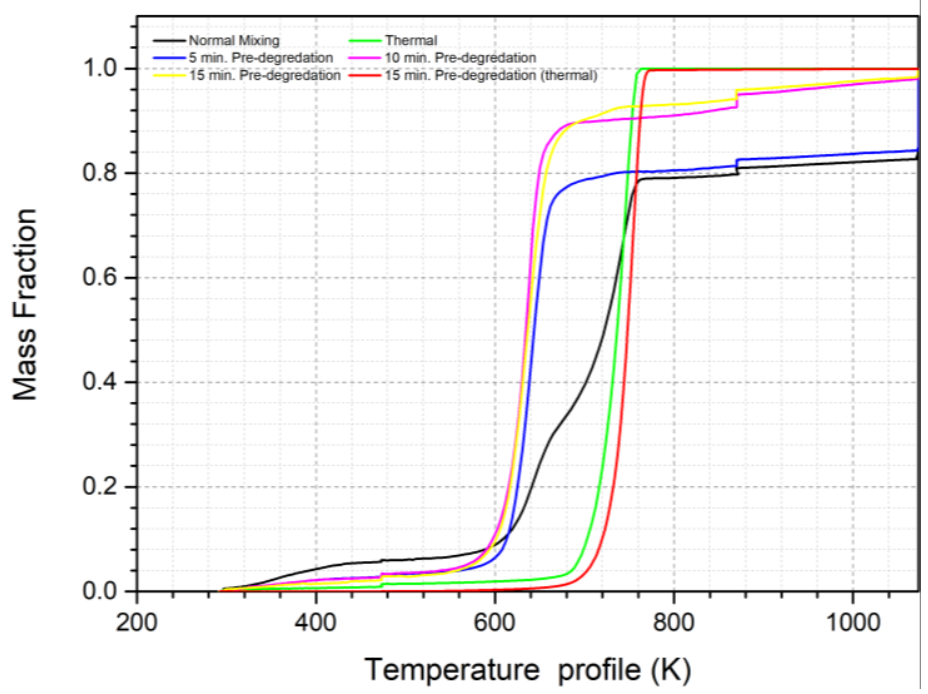

Figure 3: TGA of LLDPE thermal and catalytic degradation using normal mixing and pre-degradation; polymer mass fraction removed against temperature.

Studying carefully the results in Fig. 4, which shows the experimental pyrolysis temperature profiles for normal and pre-degradation mixing methods, the rate of the degradation is steeper and more intense as the predegradation holding increases, with the 15 min pre-degradation showing the fastest rate of IldPE degradation and normal mixing showing the slowest rate IldPE degradation.

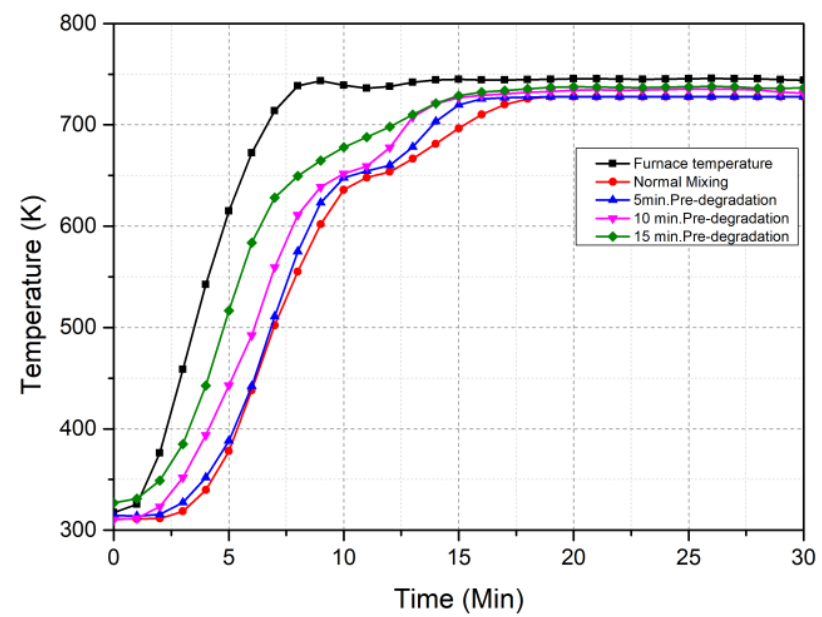

Figure 4: Temperature profile for the catalytic pyrolysis of LLDPE showing the normal mixing and predegradation reaction temperature profile 
Due to the influence of pre-degradation method in stimulating the rate and the temperature of the IldPE degradation, two set up furnace temperature programs were used. The furnace set up temperature for the normal mixing was 20 - $30 \mathrm{~K}$ higher than that of the pre-degradation mixing method. This would allow both mixing methods to reach the same final reaction temperature i.e. $723-733 \mathrm{~K}$ as used in this study.

\subsection{Effect of catalyst content}

As stated in the introduction, catalyst played an important role in the degradation of polymer. The content of the catalyst used is usually expressed as the ratio of polymer to catalyst. This ratio is very important as low ratio, i.e. high catalyst amount, may lead to overcracking, whereby more gases will be generated and higher ratio, i.e. lower catalyst amount, may yield unvolatilised solid polymer remnants at a specific reaction temperature. Manos et al. [11], reported that, the addition of more catalyst above a specific amount corresponding to a polymer-to- catalyst ratio between $1: 1$ and $2: 1$, did not increase the overall degradation rate, due to the added catalyst not being in contact with the polymer. Based on these findings three different ratios were selected for this study which include $2: 1,3: 1$ and $4: 1$. In each of the ratio, the amount of the IIdPE was maintained constant at $2.00 \mathrm{~g}$. The amount of the catalyst depends on the ratio. For instance, $1.00 \mathrm{~g}, 0.67$ $\mathrm{g}$ and $0.50 \mathrm{~g}$ of the catalyst were used for $2: 1,3: 1$ and $4: 1$ ratios respectively. The effect of catalyst content was studied at different reaction temperatures and using both, the normal mixing method as well as predegradation, as all of them have similar synergetic effect to the rate and products of the IIdPE degradation. 
Table 2. The percentage liquid and coke yield for the catalytic degradation of IldPE at different reaction temperatures and IIdPE: HY ratios using normal mixing and pre-degradation $(453 \mathrm{~K} / 5 \mathrm{~min}$ ) at $60 \mathrm{~mL} / \mathrm{min}$

\begin{tabular}{|c|c|c|c|c|c|c|c|c|c|c|c|c|}
\hline \multirow{3}{*}{ Temperature (K) } & \multicolumn{6}{|c|}{ Normal Mixing } & \multicolumn{6}{|c|}{ Pre-degradation } \\
\hline & \multicolumn{3}{|c|}{ Liquid yield (\%) } & \multicolumn{3}{|c|}{ Coke yield (\%) } & \multicolumn{3}{|c|}{ Liquid yield (\%) } & \multicolumn{3}{|c|}{ Coke yield (\%) } \\
\hline & $(2: 1$ & $3: 1$ & $4: 1$ & $2: 1$ & $3: 1$ & $4: 1$ & $2: 1$ & $3: 1$ & $4: 1$ & 2:1 & $3: 1$ & $4: 1)^{a}$ \\
\hline 623 & 14.0 & 10.0 & 9.0 & 8.0 & 17 & 24.5 & 31.0 & 47.5 & 48.5 & 6.5 & 4.5 & 3.0 \\
\hline 673 & 34.0 & 33.0 & 42 & 6.0 & 6.0 & 5.0 & 48.5 & 56.5 & 60.0 & 5.0 & 4.0 & 2.5 \\
\hline 724 & 28.0 & 34.5 & 45 & 5.0 & 4.5 & 3.5 & 45.0 & 41.5 & 46.5 & 4.0 & 3.0 & 2.0 \\
\hline
\end{tabular}

a IIdPE: HY zeolite ratio

Based on the results presented in Table 2, pre-degradation resulted in superior performance at all conditions, especially at lower temperatures. The coke amounts at the lowest temperature of $623 \mathrm{~K}$ and normal mixing at the two lowest catalyst amounts (4:1 and 3:1 polymer to catalyst ratio) included unvolatilised solid polymer remnants, which were stuck on catalyst particles and impossible to separate from them. Their presence was visible as sticky particles in the mixture. Applying pre-degradation resulted in elimination of those remnants. The trends at each temperature level and polymer to catalyst ratio are as follows. A certain amount of catalyst is required to accomplish a catalytic conversion. This means that at low catalyst amounts, adding more catalyst results in higher conversion and higher liquid yield. Above a certain amount though, catalyst amount increase leads to overcracking with the result of much smaller products being collected in the gaseous fraction. Higher reaction temperatures compensate for the catalytic effect and lead to the overcracking threshold in the catalyst amount to lower. This explain the conflicting trends regarding polymer to catalyst ratio effect at different temperatures. At $623 \mathrm{~K}$, lowest temperature, and normal mixing, as the catalyst amount increases, cracking is enhanced, resulting in higher liquid yield, which is an indication of a non-effective contact between polymer and catalyst. With the pre-degradation method as shown table 2 , the pattern has changed completely with 4:1 ratio giving the highest liquid yield and the lowest coke yield at all the reaction temperatures. The maximum liquid yield of $60.0 \%$ was obtained at the reaction temperature of $673 \mathrm{~K}$, while the lowest coke yield of $2.0 \%$ was obtained at $724 \mathrm{~K}$. An interesting point here is comparing of 4:1 ratio at lower reaction temperature $(623 \mathrm{~K})$ for the normal mixing and pre-degradation. With the pre-degradation, the liquid yield has 
increased from $9.0 \%$ to $48.5 \%$ while the coke yield has reduced from $24.5 \%$ to $3.0 \%$. This fact, revealed that, pre-degradation enhanced the cracking reaction by providing intimate contact. Akpanudoh et al. [20] varied the polymer to catalyst ratio using commercial cracking catalysts of different zeolitic content in order to investigate the acidity content effect of the whole polymer catalyst system. They carried out the catalytic degradation of IldPE over commercial cracking catalysts in a semi-batch reactor at $700 \mathrm{~K}$ with $50 \mathrm{mLN} / \mathrm{min} \mathrm{N}_{2}$ flow rate. The maximum liquid yield was observed at around $7 \%$ acidity. However, coke concentrations, were higher, as higher polymer to catalyst ratio were applied. These results were consistent with the present study at similar experimental conditions, despite different catalysts being used. Abbas-Abadi et al. [1] examined the effect of degradation temperature on the catalytic pyrolysis of IIdPE at four temperatures: 420, 450, 480 and $510{ }^{\circ} \mathrm{C}$. The results show that the residence time decreases remarkably, while the temperature of cracking increases from 420 to $510^{\circ} \mathrm{C}$. The condensed hydrocarbons show a maximum peak at $450^{\circ} \mathrm{C}$. These results also showed the same pattern as reported by present study.

\subsection{Effect of pre-degradation holding time and temperature on the IIdPE degradation products}

Pre-degradation has shown to be an effective method to improve the quantity and quality of the liquid yield and reduce or eliminate the severe deterioration of catalyst activity by coke formation. To get a broader understanding of the pre-degradation pre-treatment method, further pyrolysis experiments were conducted at different pre-degradation temperatures and holding times. Preliminary experiments show that $423 \mathrm{~K}$ is the minimal temperature at which IIdPE could melt and easily mixed with the catalyst after prolong holding time. Pre-degradation at $473 \mathrm{~K}$ showed a considerable formation of volatile products, hence 423 and $453 \mathrm{~K}$ were chosen respectively. Table 3 present the results for the liquid and coke yields obtained using normal mixing method and pre-degradation at different temperatures, holding times, IIdPE:HY ratios and carrier gas flow rates respectively. 
Table 3. The liquid and coke yields for catalytic degradation of IldPE using normal mixing method and predegradation at different temperature, holding time, IldPE: HY ratio and $\mathrm{N}_{2}$ flow rate.

\begin{tabular}{|c|c|c|c|c|c|c|c|c|c|c|c|c|}
\hline \multirow{3}{*}{$\begin{array}{l}\text { Product yield (\%) } \\
\text { Flow rate (mLN/min) } \\
\text { IldPE:HY Ratio } \\
\end{array}$} & \multicolumn{2}{|c|}{ Liquid } & \multicolumn{2}{|c|}{ Coke } & \multicolumn{2}{|c|}{ Liquid } & \multicolumn{2}{|c|}{ Coke } & \multicolumn{2}{|c|}{ Liquid } & \multicolumn{2}{|c|}{ Coke } \\
\hline & \multicolumn{4}{|c|}{0} & \multicolumn{4}{|c|}{1} & \multicolumn{4}{|c|}{10} \\
\hline & $2: 1$ & $4: 1$ & $2: 1$ & $4: 1$ & $2: 1$ & $4: 1$ & $2: 1$ & $4: 1$ & $2: 1$ & $4: 1$ & $2: 1$ & $4: 1$ \\
\hline Normal Mixing & 60.0 & 54.0 & 7.5 & 7.0 & 61.0 & 61.5 & 7.0 & 5.5 & 56.0 & 52.0 & 6.5 & 5.0 \\
\hline Pre-deg.@423 K @ 5 min & 62.5 & 58.0 & 6.0 & 5.0 & 63.0 & 73.5 & 5.5 & 4.5 & 57.5 & 60.5 & 5.0 & 3.0 \\
\hline Pre-deg. @423 K @ 10 min & 73.5 & 85.0 & 4.5 & 4.0 & 65.0 & 77.5 & 4.0 & 3.5 & 60.0 & 70.0 & 3.5 & 2.5 \\
\hline Pre-deg. @423 K @ 15 min & 72.0 & 77.5 & 4.5 & 3.5 & 61.0 & 75.5 & 3.5 & 3.0 & 59.0 & 68.5 & 3.0 & 2.0 \\
\hline Pre-deg.@453 K @ 5 min & 72.5 & 75.5 & 5.0 & 3.5 & 68.0 & 80.5 & 4.5 & 3.0 & 60.0 & 68.0 & 5.0 & 3.0 \\
\hline Pre-deg. @453 K @ 10 min & 70.5 & 72.5 & 3.5 & 3.0 & 67.5 & 75.0 & 3.5 & 2.5 & 57.5 & 67.0 & 3.0 & 2.0 \\
\hline Pre-deg. @453 K @ 15 min & 67.5 & 70.0 & 3.0 & 2.5 & 57.5 & 72.5 & 3.0 & 2.0 & 57.0 & 65.0 & 2.5 & 1.5 \\
\hline
\end{tabular}

At $0 \mathrm{~mL} / \mathrm{min} \mathrm{N}_{2}$ Flow rate, for the normal mixing, 2:1 and $4: 1$ ratio produces $60.0 \%$ and $54.0 \%$ liquid yield respectively. Comparing these results with the pre-degradation results at $423 \mathrm{~K}$ temperature and different holding times, 4:1 ratio produces the highest liquid yield except at 5 min holding time. For the pre-degradation pre-treatment method to be effective for optimal liquid yield, appropriate temperature and holding time need to be selected. At $423 \mathrm{~K}$ pre-degradation temperature, 5 min holding time is not enough for the IldPE to melt and be able to mix with the catalyst effectively. The results are similar to the normal mixing with only $3.0-4.0 \%$ increase. By extending the holding time to $10 \mathrm{~min}$, the liquid yield has increased from 54.0 to $85.0 \%$ with $4: 1$ ratio produceing the highest liquid yield. For $15 \mathrm{~min}$ holding time, the contact is extreme as in the case of higher amount of IIdPE: HY ratio leading to overcracking which favours gas formation and hence the liquid yield drops to $77.5 \%$, but the coke content decreased significantly from 7.5 and $7 \%$ to 4.5 and $3.5 \%$ for $2: 1$ and 4:1 ratio respectively. As the pre-degradation holding has increased from $5 \mathrm{~min}$ to $15 \mathrm{~min}$, the cracking reactions were more enhanced and the volatiles spent less time in the reactor. This limits the possibility of secondary reactions and hence the lower content. For the pre-degradation at higher temperature $(453 \mathrm{~K}), 5$ minutes is enough to get the appropriate contact between the IIdPE and HY catalyst, and above this holding time, the liquid yields reduces in favour of gas yield due to overcracking of the IIdPE as mentioned above.

Inert flow rate is very important parameter as it can influence the residence time, secondary reactions, overcracking and coke formation respectively. It also facilitates a better heat transfer in the system. With $0 \mathrm{mLN} / \mathrm{min}$, the carrier gas is only used prior to the start of the experiment at $100 \mathrm{mLN} / \mathrm{min}$ for $15 \mathrm{~min}$ to purge out any air trapped in the reactor. As the $\mathrm{N}_{2}$ Flow rate has increased from 0 to $1 \mathrm{~mL} / \mathrm{min}$, the heat 
transfer and the residence time in the recator have changed favouring the reaction at low polymer to catalyst ratio and pre-degradation at lower temperature and holding time. At $423 \mathrm{~K}$ pre-degradation, for 4:1 ratio, the liquid yield has increased from $54.0 \%$ to $61.5 \%$ and $58.0 \%$ to $73.5 \%$ for the normal mixing and 5 min predegradation respectively. The behaviour was the same when the holding time was changed from 5 min to 10 and 15 min respectively. With 2:1 ratio there is little decrease of the liquid yield through out as compared to 0 $\mathrm{mLN} / \mathrm{min}$ due to shifting of volatiles from liquid into gas phase.

Caldeira et al. [70] adopted a thermal homogenization step at a temperature slightly above of the melting temperature of IdPE (393 K) in order to overcome the limitations of contact surface between a solidsolid system during catalytic decomposition of IdPE. The procedure involved heating from ambient to $1073 \mathrm{~K}$ at a heating rate of $10 \mathrm{~K} \mathrm{~min}^{-1}$. To achieve the thermal homogenization, the sample was upheld isothermal at 393 $\mathrm{K}$ for $6 \mathrm{~h}$. This procedure as evaluated using TGA, exhibited only one mass loss event compared to two mass loss events without thermal homogenization for the catalytic decomposition of IdPE with HY-zeolite. This fact suggested that the thermal homogenization procedure supplied a different reaction mechanism with better accommodation of the molecules on the catalyst surface favouring the bond scission with lower coke formation and generation of lower molecular mass products, which is in agreement with the effect observed for the pre-degradation procedure [70]. The coke yield decrease is consistent across the flow rate range, as the increase in flow rate limits the possibility of secondary reactions that lead to coke formation.

With the flow rate increased from 1 to $10 \mathrm{mLN} / \mathrm{min}$ more volatiles escaped into the gas phase, due to the higher flow rate of the inert. It is obvious from the condensers arrangment, the second condenser always collected more when the flow rate is quite high. At 2:1 ratio and 5 min pre-degradation, the liquid yield decreases from $72.5>68.0>60.0 \%$ for 0,1 and $10 \mathrm{mLN} / \mathrm{min}$ respectively. With $15 \mathrm{~min}$ holding time at 4:1 ratio it decreases from $77.5>75.7>68.0 \%$ for 0,1 and $10 \mathrm{mLN} / \mathrm{min}$ respectively. The coke behaviour at 10 $\mathrm{mLN} / \mathrm{min}$ is similar to $1 \mathrm{mLN} / \mathrm{min}$ with the coke content keep on decreasing due to the more fewer secondary reactions. As the flow rate is changed from 0,1 and $10 \mathrm{~mL} / \mathrm{min}$, the coke content decreases from $6.5>5.5>5.0 \%$ and $2.5>2.0>1.5 \%$ for normal mixing and 15 min pre-degradation at $4: 1$ ratio. 


\subsection{Effect of carrier gas flow rate}

As mentioned in the previous section, the carrier gas flow rate can play a major role in fixing some important degradation parameters such as the residence time, extent of secondary reactions and the percentage products yield. To get more details on the role of the carrier gas on the degradation of IldPE, 5 min predegradation at $453 \mathrm{~K}$ with 4:1 IIdPE to HY ratio was chosen and compared with thermal degradation and normal mixing at $0,1,10,20,30$ and $60 \mathrm{mLN} / \mathrm{min}$ as shown in Table 4 .

Table 4. The liquid and coke yields for thermal and catalytic degradation of IIdPE using normal mixing method and pre-degradation at different $\mathrm{N}_{2}$ flow rate.

\begin{tabular}{|c|c|c|c|c|c|c|}
\hline \multirow[b]{2}{*}{$\begin{array}{l}\text { Flow rate } \\
(\mathrm{ml} / \mathrm{min})\end{array}$} & \multicolumn{2}{|c|}{ Thermal } & \multicolumn{2}{|c|}{ Normal Mixing } & \multicolumn{2}{|c|}{ Pre-degradation } \\
\hline & $\begin{array}{l}\text { Liquid yield } \\
\text { (\%) }\end{array}$ & $\begin{array}{l}\text { Polymer } \\
\text { Unvolitilised } \\
\text { Remnants } \\
(\%) \\
\end{array}$ & $\begin{array}{l}\text { Liquid yield } \\
\text { (\%) }\end{array}$ & $\begin{array}{l}\text { Coke } \\
\text { yield } \\
\text { (\%) }\end{array}$ & $\begin{array}{l}\text { Liquid yield } \\
\text { (\%) }\end{array}$ & $\begin{array}{l}\text { Coke } \\
\text { yield } \\
(\%)\end{array}$ \\
\hline 0 & 45.0 & 39.5 & 54.0 & 7.0 & 75.5 & 3.5 \\
\hline 1 & 46.0 & 37.5 & 61.5 & 5.5 & 80.5 & 3.0 \\
\hline 10 & 52.5 & 32.0 & 52.0 & 5.0 & 68.0 & 3.0 \\
\hline 20 & 64.0 & 19.5 & 50.0 & 4.5 & 59.5 & 2.0 \\
\hline 30 & 70.0 & 10.0 & 47.5 & 4.0 & 56.0 & 2.0 \\
\hline 60 & 75.0 & 7.5 & 45.0 & 3.5 & 46.5 & 2.0 \\
\hline
\end{tabular}

For thermal degradation as shown in table 4, more conversions were achieved by varying the flow rate from 0 $-60 \mathrm{mLN} / \mathrm{min}$. For the liquid yield, it changes from $45.0 \%<46.0 \%<52.5 \%<64.0 \%<70.0 \%<75.0 \%$ for 0,1 , $10,20,30$ and $60 \mathrm{mLN} / \mathrm{min}$ respectively. For the coke yield, it changes from $39.5 \%<37.5 \%<32.0 \%<19.5 \%<$ $10.0 \%<7.5 \%$ for $0,1,10,20,30$ and $60 \mathrm{mLN} / \mathrm{min}$ respectively. Most of these coke were unconverted IldPE, due to the temperature used for this study i.e. $723-733 \mathrm{~K}$ is not enough for complete thermal degradation of IldPE.

For the normal mixing with $4: 1$ ratio, $1 \mathrm{~mL} / \mathrm{min}$ gave the optimal liquid yield of $61.5 \%$ and then decreses with increase in flow rate with the lowest liquid yield of $45.0 \%$ recorded at $60 \mathrm{mLN} / \mathrm{min}$. This is due to 
the loss of the volatiles into the gaseous phase as explained before. The coke content diminishes as the flow rate increses, with $7.0 \%$ at $0 \mathrm{mLN} / \mathrm{min}$ and $3.5 \%$ at $60 \mathrm{mLN} / \mathrm{min}$. With the pre-degradation, the liquid yield also exhibited maxima at $1 \mathrm{~mL} / \mathrm{min}$. Both the liquid and coke yield expressed similar pattern as in the case of the normal mixing. At all the flow rate, the pre-degradation gives a better liquid yield and less coke content. One of the important result from this study, is the results at $0 \mathrm{mLN} / \mathrm{min}$. This indicated that, pyrolysis can be carried without the carrier gas, reducing the expense of the process.

\subsection{Coked catalyst characterisation}

In catalytic degradation, a significant portion of the feedstock is converted to coke deposited on the catalyst. It was necessary to characterize the nature of this process because of its commercial importance. Coke formation have long been recognized as the most prevailing reason for practical zeolite catalyst deactivation leading to significant problems of great technical, economic, and environmental concerns. Several techniques have been employed to get the information about, the amount, composition, chemical nature and location of the coke. Most of these techniques were complex, time consuming and destructive. Thermogravimetric analysis (TGA) is widely used to quantify the amount of coke on a surface, and to characterise the composition of carbonaceous materials in terms of their fixed carbon content, moisture, ash content and volatile components [71] [72] [73].

To further, explore the influential role of the pre-degradation pre-treatment method on the degradation of IIdPE. Coked catalysts at lower experimental temperature i.e. $623 \mathrm{~K}$ were characterised for their coke/unconverted polymer, as shown in Figs. 5 and 6.

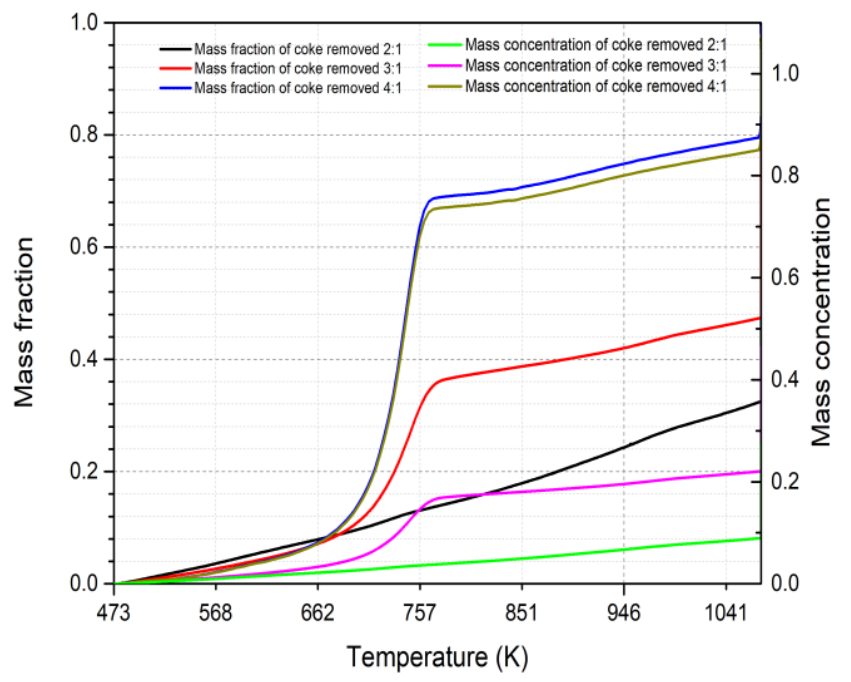


Figure 5: TGA of coked samples from catalytic pyrolysis at $623 \mathrm{~K}, 60 \mathrm{~mL} / \mathrm{min}$ at different IldPE: HY ratio using normal mixing

Fig. 5 contains both the coke fraction and coke concentration. The coke concentration is very important parameter especially when comparing the coke content of coked catalysts with different catalyst content. For 3:1 and 4:1 ratios, they show peaks corresponding to the peak for the TGA of the fresh IIdPE, which confirmed the presence of unconverted polymer. For the ratio $2: 1$, the degradation is complete and contained no any unconverted polymer but has high percentage of hard coke due to the slow rate of the IldPE degradation which encourages the prevalence of secondary reaction and hence the high rate of coke formation. The pattern of the coke concentration is similar to the coke fraction, with 4:1 ratio being overburden due to the presence of the unconverted IIdPE.

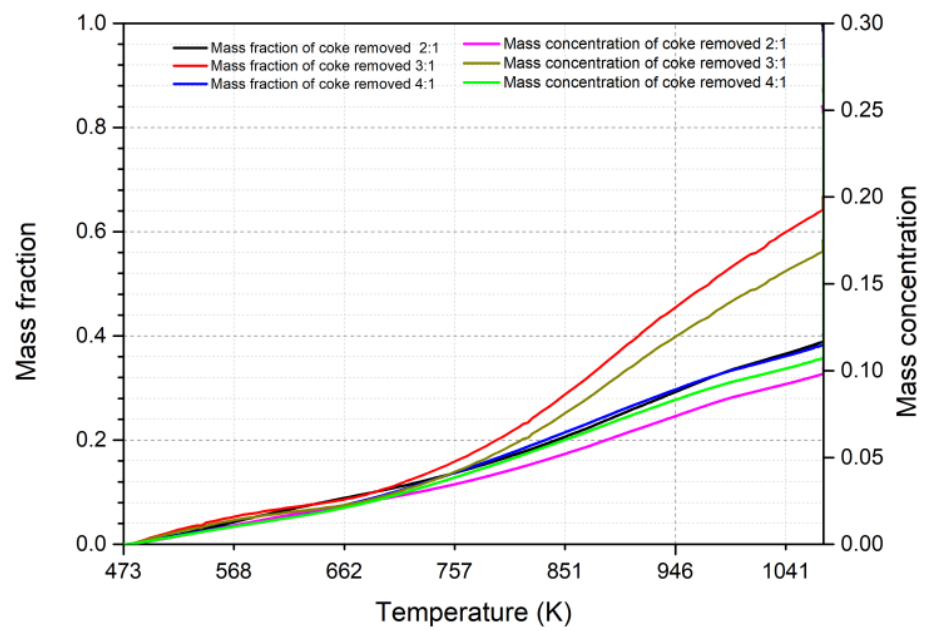

Figure 6: TGA of coked samples from catalytic pyrolysis at $623 \mathrm{~K}, 60 \mathrm{~mL} / \mathrm{min}$ at different IldPE: HY ratio using pre-degradation at $453 \mathrm{~K} / 5 \mathrm{~min}$

With the pre-degradation as shown in Fig. 6, the picture has changed completely with all the ratios attaining complete conversion as no any sign of unconverted LLDPE. For the 2:1 ratio, pre-degradation has help to reduce the content of the hard coke by $10 \%$ and the coke concentration from 0.27 to 0.25 . 


\subsection{Liquid sample characterisation}

The liquid sample characterisation was carried out using a non-polar capillary column, which aids in the separation of the components of the liquid product mixture according to their volatility/boiling point. Due to the complexity of the components samples, the results discussion would be based in three-component groups i.e. the lighter fractions, which include the components in the boiling point range from $\mathrm{C}_{4}-\mathrm{C}_{9}(272.70 \mathrm{~K}-$ $424.00 \mathrm{~K})$, the middle fractions, which include the components from $\mathrm{C}_{9}-\mathrm{C}_{14}(424.00 \mathrm{~K}-526.70 \mathrm{~K})$ and the heavier fractions, which include the components from $\mathrm{C}_{14}-\mathrm{C}_{20}(526.70 \mathrm{~K}-617.00 \mathrm{~K})$. This will provide a better overview and makes it easier to compare between different results.

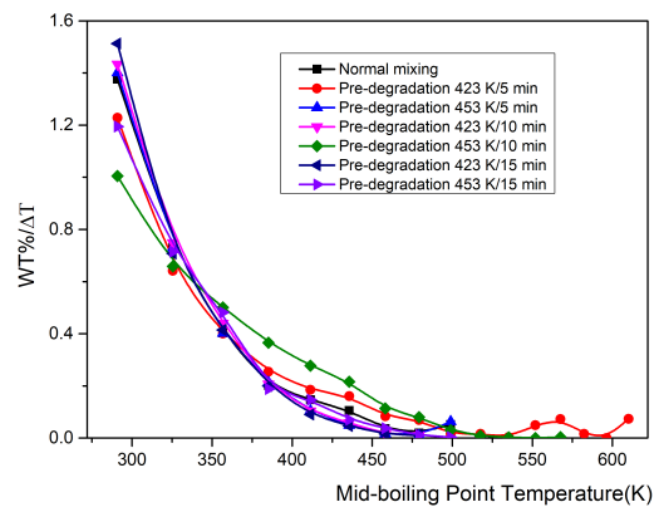

Figure 7: Boiling point distribution of the liquid fractions from the catalytic degradation of IldPE using normal mixing method and pre-degradation at different temperature and holding time with 2:1 polymer to catalyst ratio and $0 \mathrm{~mL} / \mathrm{min} \mathrm{N}_{2}$ flow rate

All the samples presented in Fig. $7\left(0 \mathrm{mLN} / \mathrm{min} \mathrm{N}_{2}\right.$ flow rate, 2:1 ratio) showed higher percentage of light fractions and moderate amount of middle fractions with very few heavy fractions. The low flow rate used and higher ratio of polymer to catalyst accounted for these results. The removal of products from the reactor was relatively slow allowing them to undergo secondary reactions enhancing overcracking. On the other hand, the pre-degradation has helped to increase more of the gasoline and the kerosene fractions as shown by the predegradation at $453 \mathrm{~K} / 10 \mathrm{~min}$. 


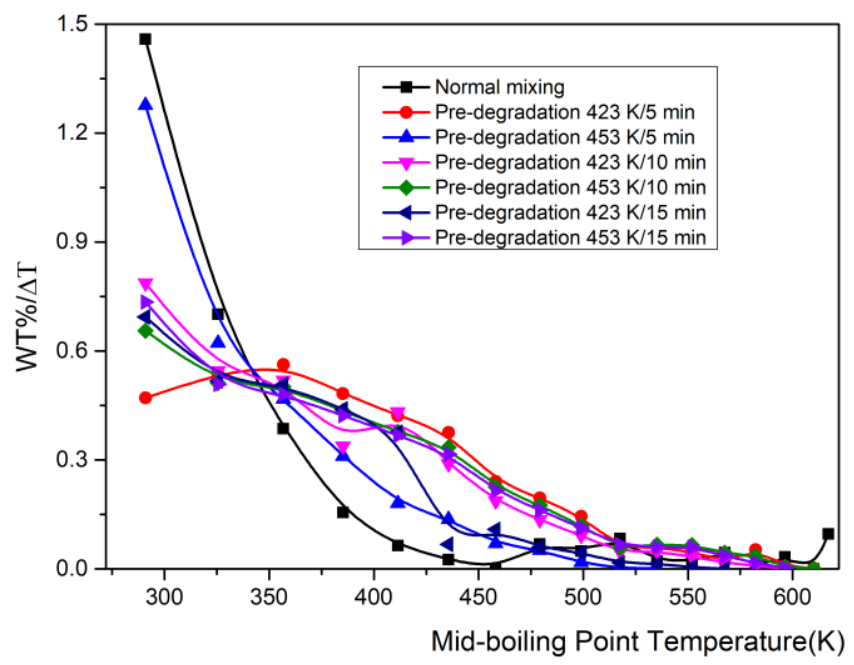

Figure 8: Boiling point distribution of the liquid fractions from the catalytic degradation of IldPE using normal mixing method and pre-degradation at different temperature and holding time with 4:1 polymer to catalyst ratio and $0 \mathrm{~mL} / \mathrm{min} \mathrm{N}_{2}$ flow rate

With the 4:1 ratio as presented in Fig. 8, the product distribution pattern has slightly changed in favour of light and middle fractions with more gasoline and kerosene fractions, except with normal mixing and predegradation at $453 \mathrm{~K} / 10 \mathrm{~min}$, which they showed significant amount of lighter fractions.

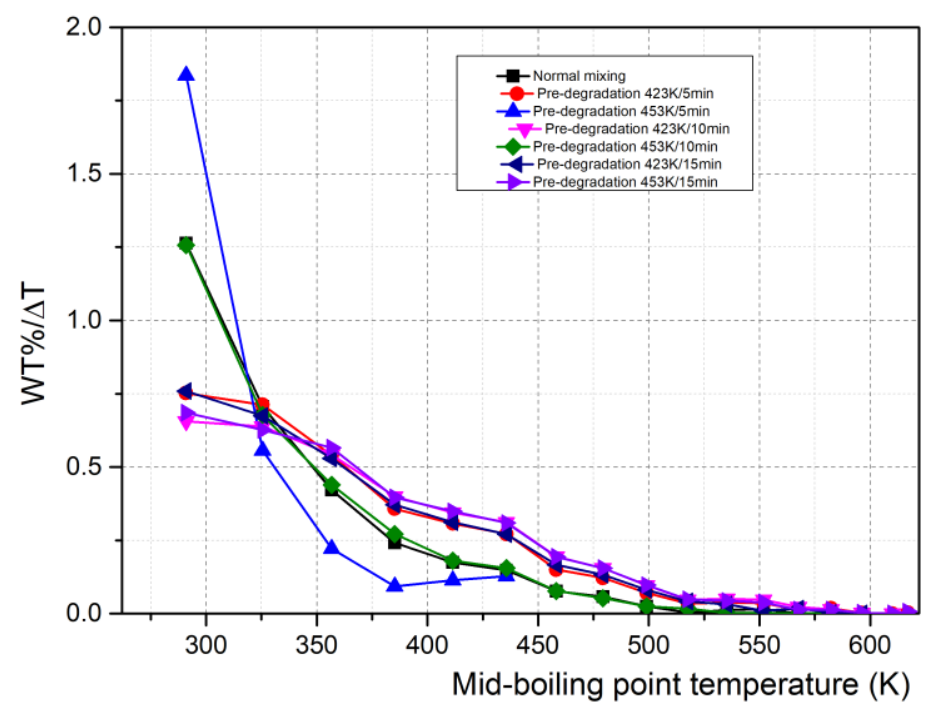

Figure 9: Boiling point distribution of the liquid fractions from the catalytic degradation of IldPE using normal mixing method and pre-degradation at different temperature and holding time with 2:1 $\mathrm{r}$ polymer to catalyst atio and $1 \mathrm{~mL} / \mathrm{min} \mathrm{N}_{2}$ flow rates 
By increasing the flow rate from 0 to $1 \mathrm{~mL} / \mathrm{min}$ as shown in Fig. 9, the amount of lighter fractions has decreased favouring more of gasoline and kerosene fractions (middle fractions) except with the predegradation at $453 \mathrm{~K} / 5$ min which maintains similarly high lighter fractions.

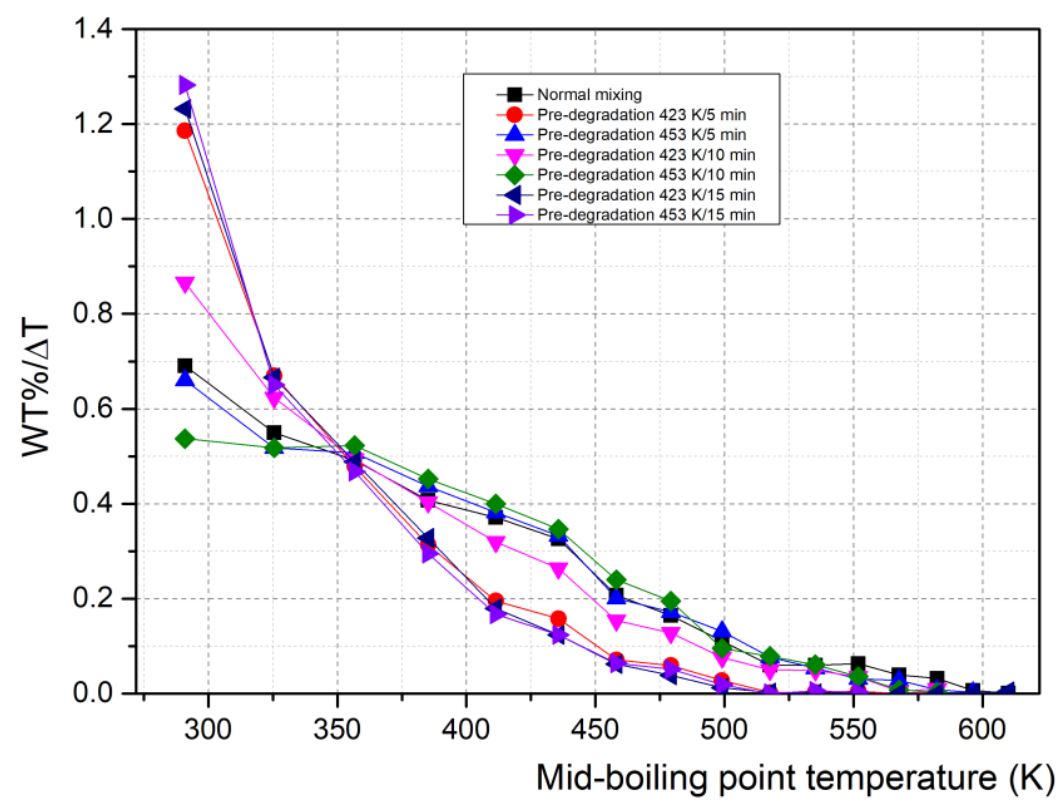

Figure 10: Boiling point distribution of the liquid fractions from the catalytic degradation of IldPE using normal mixing method and pre-degradation at different temperature and holding time with 4:1 polymer to catalyst ratio and $1 \mathrm{~mL} / \mathrm{min} \mathrm{N}_{2}$ flow rates

With 4:1 ratio at $1 \mathrm{mLN} / \mathrm{min}$ as presented in Fig. 10, the product distribution has shifted to middle fractions, with more gasoline and kerosene fractions. 


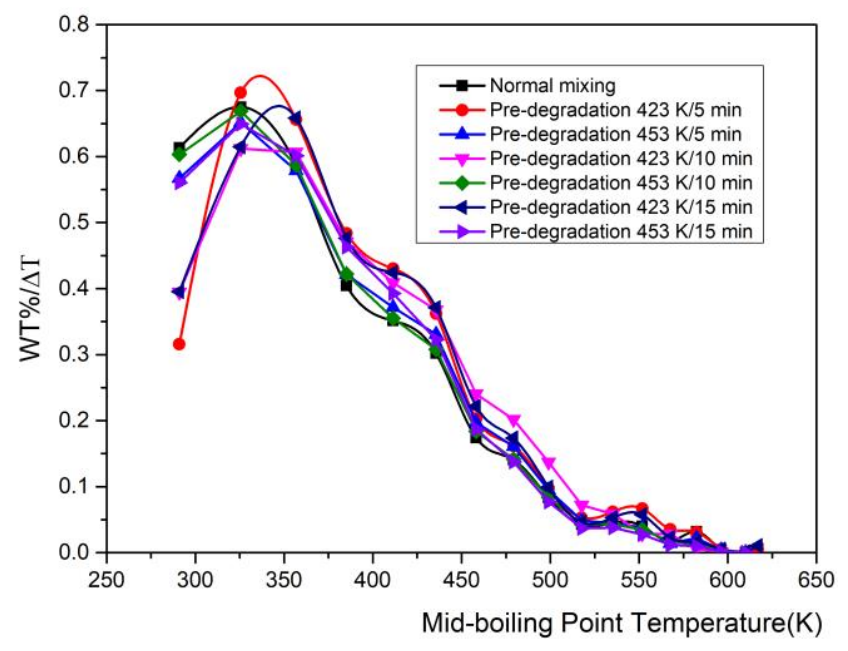

Figure 11: Boiling point distribution of the liquid fractions from the catalytic degradation of IIdPE using normal mixing method and pre-degradation at different temperature and holding time with 2:1 polymer to catalyst ratio and $10 \mathrm{~mL} / \mathrm{min} \mathrm{N}_{2}$ flow rate

Fig. 11 shows the results obtained with $10 \mathrm{~mL} / \mathrm{min}$ flow rate. The amount of the lighter fractions has declined showing a peak at the gasoline range fractions with more middle fractions and very few heavy fractions. Lin and Yang [17] have also observed similar behaviour when the flow rate was increased with lower $C_{1}-$ $\mathrm{C}_{4}$ hydrocarbon gases and higher liquid yields.

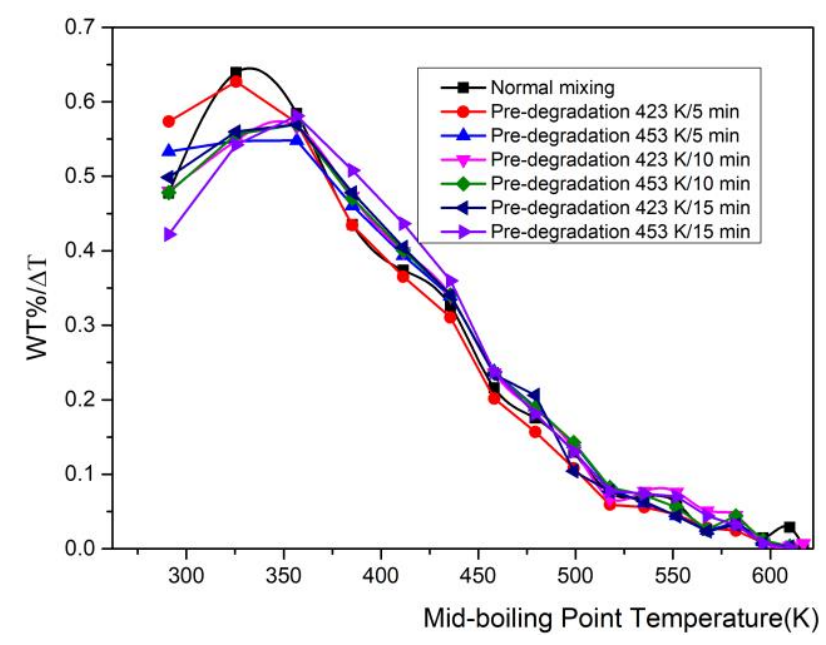

Figure 12: Boiling point distribution of the liquid fractions from the catalytic degradation of IldPE using normal mixing method and pre-degradation at different temperature and holding time with 4:1 polymer to catalyst ratio and $10 \mathrm{~mL} / \mathrm{min} \mathrm{N}_{2}$ flow rate

For the 4:1 ratio at $10 \mathrm{~mL} / \mathrm{min} \mathrm{N}_{2}$ flow rate as presented by Fig. 12, the behaviour is similar to 2:1 ratio with little decline of the lighter fractions and little increase of the heavy fractions. 


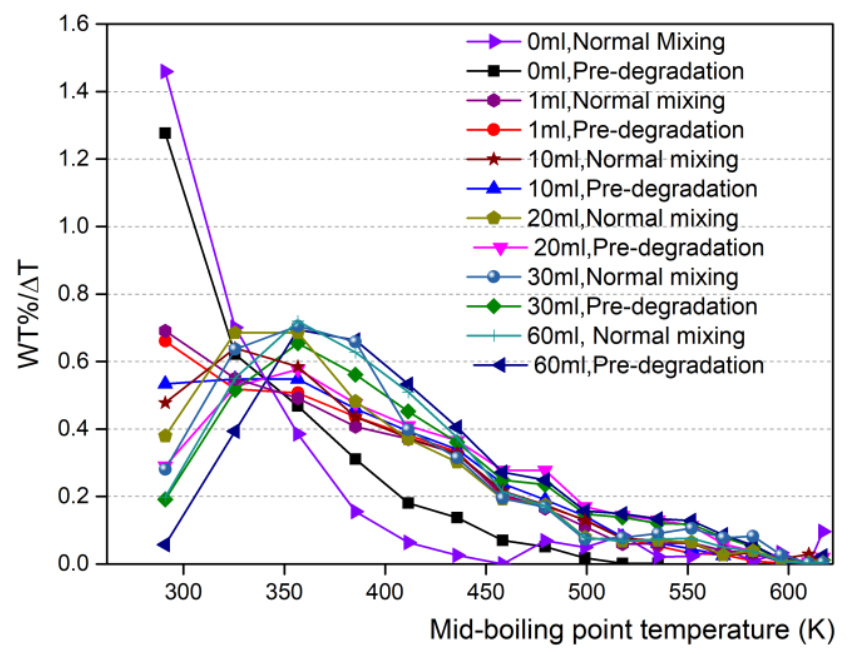

Figure 13: Boiling point distribution of the liquid fractions from the catalytic degradation of IldPE using normal mixing method and pre-degradation at different $\mathrm{N}_{2}$ flow rates

Fig. 13 looked at the effect of the carrier gas flow rate in more details using normal mixing and predegradation at $453 \mathrm{~K} / 5 \mathrm{~min}$. The difference between 0 and $60 \mathrm{mLN} / \mathrm{min} \mathrm{N}_{2}$ flow rates is very visible. With 0 $\mathrm{mL} / \mathrm{min}$ flow rate, the product distribution started with higher amount of lighter fractions and decreased sharply towards the middle and heavy fractions. For the $60 \mathrm{mLN} / \mathrm{min}$ flow rate, the product distributions decline initially at lighter fractions then reach maxima at the gasoline fractions and then slowly decreases as it moves toward the heavy fractions. This is a clear sign of more secondary reactions with $0 \mathrm{~mL} / \mathrm{min}$ flow rate due to the longer residence time of the products in the reactor while the opposite case is true with the highest flow rate. In both cases, the products with pre-degradation were of better quality and fitted within the gasoline and kerosene fractions. Elordi et al. [74] reported that, HY- zeolites maximize the production of middle distillates.

As the flow rate changed from 0 to $1 \mathrm{~mL} / \mathrm{min}$, the product distribution changed with more stability across the lighter and the middle fractions as it decreases slowly toward heavier fractions. With the $20 \mathrm{~mL} / \mathrm{min}$ flow rate, the behaviour is similar to the $60 \mathrm{mLN} / \mathrm{min}$ flow rate but the margins between the normal mixing and the pre-degradation is bigger with the normal mixing showing higher maxima at the gasoline range fractions but decreasing abruptly compared to the pre-degradation. This is evidence of more overcracking with the predegradation mixing because due to intimate contact between the IldPE and the catalyst. With $10 \mathrm{mLN} / \mathrm{min}$ flow rate the normal mixing has lower content of lighter fractions compared to the pre-degradation, but has a peak at gasoline range fractions. For the higher flow rate of $30 \mathrm{mLN} / \mathrm{min}$ the pattern is similar to the product 
distribution of $10 \mathrm{~mL} / \mathrm{min}$, but the pre-degradation decline slowly as proceeded from the middle fractions to the heavier fractions whereas the normal mixing decline suddenly. The possible reason for this behaviour with the normal mixing could be due to the presence of appreciable thermal cracking, because of the poor contact between the polymer and catalyst. In pre-degradation, it is supposed to be almost purely catalytic cracking due to the intimate contact between the polymer and catalyst.

\section{Conclusions}

The use of pre-degradation pre-treatment method as demonstrated by this study enhances the catalytic degradation of IIdPE by improving the contact between the polymer and the catalyst. Pre-degradation resulted into higher liquid yield, and lower coke formation. This method could also be useful in co-pyrolysis of polymer with heavy oil and biomass where the main objective is to adjust the heavy fractions from other components by synergetic effect of mixing with the hydrogen rich polymer. Furthermore, pre-degradation lowers the pyrolysis temperature making it more economical and viable method for IIdPE pyrolysis. The improved behavior delivered by this method is due to the intimate contact between IIdPE and the catalyst. Moreover, pre-degradation enables the effective low temperature pyrolysis even in the absence of carrier gas.

\section{Acknowledgement}

Financial support received from Petroleum Technology Development Fund (PTDF) for the sponsor of this research is gratefully acknowledged.

\section{References}

[1] M.S. Abbas-Abadi, M.N. Haghighi, H. Yeganeh, The effect of temperature, catalyst, different carrier gases and stirrer on the produced transportation hydrocarbons of LLDPE degradation in a stirred reactor, Journal of Analytical and Applied Pyrolysis 95 (2012) 198-204. https://doi.org/10.1016/i.jaap.2012.02.007

[2] C. Kassargy, S. Awad, G. Burnens, K. Kahine, M. Tazerout, Gasoline and diesel-like fuel production by continuous catalytic pyrolysis of waste polyethylene and polypropylene mixtures over USY zeolite, Fuel 224 (2018) 764-773. https://doi.org/10.1016/i.fuel.2018.03.113

[3] D. M. Simpson, G. A. Vaughan, Exxon Mobil Chemical Company, Ency. Polym. Sci. Tech., Ethylene Polymers LLDPE, 2000. https://www.scribd.com/document/192560025/Ethylene-Polymers-LLDPE

[4] Plastics-The Facts, An Analysis of European Plastics Production, Demand and Waste Data, Plastic Europe, EuPC, EuPR and EPRO, 2016. https://www.plasticseurope.org/en/resources/market-data

[5] Plastics-The Facts, An Analysis of European Plastics Production, Demand and Waste Data, Plastic Europe, EuPC, EuPR and EPRO, 2017. https://www.plasticseurope.org/en/resources/market-data

[6] C. Muhammad, J.A. Onwudili, P.T. Williams, Thermal degradation of real-world waste plastics and simulated mixed plastics in a two-stage pyrolysis-catalysis reactor for fuel production, Energy and Fuels 29 (2015) 2601 -2609. https://pubs.acs.org/doi/ipdf/10.1021/ef502749h 
[7] J. Malinauskaite, H. Jouhara, D. Czajczyńska, P. Stanchev, E. Katsou, P. Rostkowski, R. J. Thorne, J. Colón, S. Ponsá, F. Al-Mansour, L. Anguilano, Municipal solid waste management and waste-to-energy in the context of a circular economy and energy recycling in Europe, Energy 141 (2017) 2013 -2044.

https://doi.org/10.1016/i.energy.2017.11.128

[8] J. Yu, L. Sun, C. Ma, Y. Qiao, H. Yao, Thermal degradation of PVC: A review, Waste Management 48 (2016) 300-314. https://doi.org/10.1016/i.wasman.2015.11.041

[9] M. Kamboj, Degradation of plastics for clean environment, International Journal of Advanced Research in Engineering and Applied Sciences 5 (2016) 1-19. http://www.garph.co.uk/IJAREAS/Mar2016/2.pdf

[10] K. Gobin, G. Manos, Polymer degradation to fuels over microporous catalysts as a novel tertiary plastic recycling method, Polymer Degradation and Stability 83 (2004) 267-279

https://doi.org/10.1016/S0141-3910(03)00272-6

[11] G. Manos, A. Garforth, J. Dwyer, Catalytic degradation of high-density polyethylene on an ultrastable-Y zeolite. Nature of initial polymer reactions, pattern of formation of gas and liquid products, and temperature effects, Industrial Engineering and Chemistry Research 39 (2000) 1203-1208.

https://pubs.acs.org/doi/abs/10.1021/ie990513i

[12] S. L. Wong, N. Ngadi, T. A. T. Abdullah, I. M. Inuwa, Current state and future prospects of plastic waste as source of fuel: A review, Renewable and Sustainable Energy Reviews 50 (2015) 1167-1180.

https://doi.org/10.1016/j.rser.2015.04.063

[13] P. T. Benavides, P. Sun, J. Han, J. B. Dunn, M. Wang, Life-cycle analysis of fuels from post-use non-recycled plastics, Fuel 203 (2017) 11-22. https://doi.org/10.1016/j.fuel.2017.04.070

[14] J. K. Fink, Pyrolysis and combustion of polymer wastes in combination with metallurgical processes and the cement industry, Journal of Analytical and Applied Pyrolysis 51 (1999) 239-252.

https://doi.org/10.1016/S0165-2370(99)00019-4

[15] G. Manos, I. Y. Yusof, N. H. Gangas, N. Papayannakos, Tertiary recycling of polyethylene to hydrocarbon fuel by catalytic cracking over aluminum pillared clays, Energy and Fuels 16 (2002) 485-489.

https://pubs.acs.org/doi/abs/10.1021/ef0102364

[16] G. Manos, I. Y. Yusof, N. Papayannakos, N. H. Gangas, Catalytic cracking of polyethylene over clay catalysts. Comparison with an ultrastable Y zeolite, Industrial and engineering chemistry research 40 (2001) 2220-2225. https://pubs.acs.org/doi/abs/10.1021/ie001048o

[17] Y. H. Lin, M. H. Yang, Tertiary recycling of commingled polymer waste over commercial FCC equilibrium catalysts for producing hydrocarbons, Polymer Degradation and Stability 94 (2009) 25-33.

https://doi.org/10.1016/i.polymdegradstab.2008.10.018

[18] N. Miskolczi, L. Bartha, G. Deák, Thermal degradation of polyethylene and polystyrene from the packaging industry over different catalysts into fuel-like feed stocks, Polymer degradation and stability 91 (2006) 517526. https://doi.org/10.1016/j.polymdegradstab.2005.01.056

[19] G. Manos, A. Garforth, J. Dwyer, Catalytic degradation of high-density polyethylene over different zeolitic structures, Industrial and engineering chemistry research 39 (2000) 1198-1202.

https://pubs.acs.org/doi/abs/10.1021/ie990512q

[20] N. S. Akpanudoh, K. Gobin, G. Manos, Catalytic degradation of plastic waste to liquid fuel over commercial cracking catalysts: effect of polymer to catalyst ratio/acidity content, Journal of Molecular Catalysis A: Chemical 235 (2005) 67-73. https://doi.org/10.1016/j.molcata.2005.03.009

[21] G. Lopez, M. Artetxe, M. Amutio, J. Bilbao, M. Olazar, Thermochemical routes for the valorization of waste polyolefinic plastics to produce fuels and chemicals: A review, Renewable and Sustainable Energy Reviews 73 (2017) 346-368. https://doi.org/10.1016/i.rser.2017.01.142

[22] C. Pedro, G. Elordi, M. Olazar, T. A. Aguayo, B. Pawelec, J. Bilbao, Insights into the coke deposited on $\mathrm{HZSM}-5, \mathrm{H} \beta$ and $\mathrm{HY}$ zeolites during the cracking of polyethylene, Applied Catalysis B: Environmental 104 (2011) 91-100 https://doi.org/10.1016/i.apcatb.2011.02.024

[23] K. Murata, M. Brebu, Y. Sakata, The effect of silica-alumina catalysts on degradation of polyolefins by a continuous flow reactor, Journal of Analytical and Applied Pyrolysis, 89 (2010) 30-38.

https://doi.org/10.1016/j.jaap.2010.05.002

[24] M. Artetxe, G. Lopez, M. Amutio, G. Elordi, M. Olazar, J. Bilbao, Operating conditions for the pyrolysis of poly- (ethylene terephthalate) in a conical spouted-bed reactor, Industrial \& Engineering Chemistry Research, 49 (2010) 2064-2069. https://pubs.acs.org/doi/pdf/10.1021/ie900557c

[25] K. Murata, K. Sato, Y. Sakata, Effect of pressure on thermal degradation of polyethylene, Journal of Analytical and Applied Pyrolysis, 71 (2004) 569-589. https://doi.org/10.1016/i.jaap.2003.08.010 
[26]_P. T. Williams, E. A. Williams, Interaction of plastics in mixed-plastics pyrolysis, Energy and Fuels, 13 (1999) 188-196. https://pubs.acs.org/doi/10.1021/ef980163x

[27] E. A. Williams, P.T. Williams, The pyrolysis of individual plastics and a plastic mixture in a fixed bed reactor, Journal of Chemical Technology and Biotechnology: International Research in Process, Environmental and Clean Technology, 70 (1997) 9-20. https://onlinelibrary.wiley.com/doi/abs/10.1002/(SICI)10974660(199709)70:1\%3C9::AID-JCTB700\%3E3.0.CO;2-E

[28] P. Onu, C. Vasile, S. Ciocılteu, E. Iojoiu, H. Darie, Thermal and catalytic decomposition of polyethylene and polypropylene, Journal of Analytical and Applied pyrolysis 49 (1999)145-153.

https://doi.org/10.1016/S0165-2370(98)00109-0

[29] C. Vasile, H. Pakdel, B. Mihai, P. Onu, H. Darie, S. Ciocâlteu, Thermal and catalytic decomposition of mixed plastics, Journal of analytical and Applied Pyrolysis 57 (2001) 287-303.

https://doi.org/10.1016/S0165-2370(00)00151-0

[30] S. M. Al-Salem, A. Antelava, A. Constantinou, G. Manos, A. Dutta, A review on thermal and catalytic pyrolysis of plastic solid waste (PSW), Journal of environmental management 197 (2017) 177-198.

https://doi.org/10.1016/i.jenvman.2017.03.084

[31] W. Kaminsky, M. Predel, A. Sadiki, Feedstock recycling of polymers by pyrolysis in a fluidised bed, Polymer Degradation and Stability $85 \quad$ (2004) https://doi.org/10.1016/j.polymdegradstab.2003.05.002

[32] S. H. Jung, M. H. Cho, B. S. Kang, J. S. Kim, Pyrolysis of a fraction of waste polypropylene and polyethylene for the recovery of BTX aromatics using a fluidized bed reactor, Fuel Processing Technology, 91(2010) 277-284. https://doi.org/10.1016/i.fuproc.2009.10.009

[33] P. N. Sharratt, Y. H. Lin, A. A. Garforth, J. Dwyer, Investigation of the catalytic pyrolysis of high-density polyethylene over a HZSM-5 catalyst in a laboratory fluidized-bed reactor, Industrial and engineering chemistry research 36 (1997) 5118-5124. https://pubs.acs.org/doi/abs/10.1021/ie970348b

[34] F. J. Mastral, E. Esperanza, P. Garcia, M. Juste, Pyrolysis of high-density polyethylene in a fluidised bed reactor, Influence of the temperature and residence time, Journal of Analytical and Applied Pyrolysis 63(2002) 1-15. https://doi.org/10.1016/S0165-2370(01)00137-1

[35] G. Elordi, M. Olazar, G. Lopez, M. Artetxe, J. Bilbao, Product yields and compositions in the continuous pyrolysis of high-density polyethylene in a conical spouted bed reactor, Industrial and Engineering Chemistry Research 50(2011) 6650-6659. https://pubs.acs.org/doi/abs/10.1021/ie200186m

[36] G. Elordi, M. Olazar, P. Castaño, M. Artetxe, J. Bilbao, Polyethylene cracking on a spent FCC catalyst in a conical spouted bed, Industrial and Engineering Chemistry Research 51 (2012) 14008-14017.

https://pubs.acs.org/doi/abs/10.1021/ie3018274

[37] M. Amutio, G. Lopez, M. Artetxe, G. Elordi, M. Olazar, J. Bilbao, Influence of temperature on biomass pyrolysis in a conical spouted bed reactor, Resources, Conservation and Recycling 59 (2012) 23-31.

https://doi.org/10.1016/j.resconrec.2011.04.002

[38] M. Arabiourrutia, G. Elordi, G. Lopez, E. Borsella, J. Bilbao, M. Olazar, Characterization of the waxes obtained by the pyrolysis of polyolefin plastics in a conical spouted bed reactor, Journal of Analytical and Applied Pyrolysis 94 (2012) 30-237. https://doi.org/10.1016/j.jaap.2011.12.012

[39] G. Lopez, M. Amutio, G. Elordi, M. Artetxe, H. Altzibar, M. Olazar, A conical spouted bed reactor for the valorisation of waste tires, Proc: 13th International Conference on Fluidization - New Paradigm in Fluidization Engineering, May 16-21, Gyeong-ju, Korea (2010). http://dc.engconfintl.org/fluidization xiii/87/

[40] J. Aguado, D. P. Serrano, J. M. Escola, A. Peral, Catalytic cracking of polyethylene over zeolite mordenite with enhanced textural properties, J. Analytical Applied Pyrolysis 85 (2009)3 52-358

https://doi.org/10.1016/i.jaap.2008.10.009

[41] C. Ludlow-Palafox, H. A. Chase, Microwave-induced pyrolysis of plastic wastes, Industrial and engineering chemistry research 40 (2001) 4749-4756. https://pubs.acs.org/doi/abs/10.1021/ie010202i

[42] A. Undri, L. Rosi, M. Frediani, P. Frediani, Efficient disposal of waste polyolefins through microwave assisted pyrolysis, Fuel, 116 (2014) 662-671. https://doi.org/10.1016/i.fuel.2013.08.037

[43] Z. Hussain, K. M. Khan, N. Basheer, Co-liquefaction of Makarwal coal and waste polystyrene by microwave-metal interaction pyrolysis in copper coil reactor, Journal of Analytical and Applied Pyrolysis 90 (2011) 53-55.

https://doi.org/10.1016/i.jaap.2010.10.002

[44] X. Zhang, H. Lei, G. Yadavalli, L. Zhu, Y. Wei, Y. Liu, Gasoline-range hydrocarbons produced from microwave-induced pyrolysis of low-density polyethylene over ZSM-5, Fuel 144 (2015) 33-42.

https://onlinelibrary.wiley.com/doi/abs/10.1002/9783527684403.ch3 
[45] A. Undri, M. Frediani, L. Rosi, P. Frediani, Reverse polymerization of waste polystyrene through microwave assisted pyrolysis, Journal of Analytical and Applied Pyrolysis 105 (2014) 35-42.

https://doi.org/10.1016/j.jaap.2013.10.001

[46] R. R. Guddeti, R. Knight, E. D. Grossmann, Depolymerization of polyethylene using induction-coupled plasma technology, Plasma Chemistry and Plasma Processing 20 (2000) 37-64.

https://link.springer.com/article/10.1023\%2FA\%3A1006969710410

[47] R. R. Guddeti, R. Knight, E. D. Grossmann,_Depolymerization of polypropylene in an induction-coupled plasma (ICP) reactor, Industrial and engineering chemistry research 39 (2000) 1171-1176.

https://pubs.acs.org/doi/abs/10.1021/ie9906868

[48] P. G. Rutberg, V. A. Kuznetsov, E. O. Serba, S. D. Popov, A. V. Surov, G. V. Nakonechny, A. V. Nikonov, Novel three-phase steam-air plasma torch for gasification of high-caloric waste, Applied energy 108 (2013) 505-514. https://doi.org/10.1016/i.apenergy.2013.03.052

[49] M. Stelmachowski, Feedstock recycling of waste polymers by thermal cracking in molten metal: thermodynamic analysis, Journal of Material Cycles and Waste Management 16 (2014) 211-218.

https://link.springer.com/article/10.1007\%2Fs10163-013-0178-x

[50] M. Stelmachowski, Thermal conversion of waste polyolefins to the mixture of hydrocarbons in the reactor with molten metal bed, Energy Conversion and Management 51 (2010) 2016-2024.

https://doi.org/10.1016/j.enconman.2010.02.035

[51] A. López, I. De Marco, B. M. Caballero, M. F. Laresgoiti, A. Adrados, Influence of time and temperature on pyrolysis of plastic wastes in a semi-batch reactor, Chemical Engineering Journal 173 (2011) 62-71.

https://doi.org/10.1016/i.cej.2011.07.037

[52] G. Yan, X. Jing, H. Wen, S. Xiang, Thermal cracking of virgin and waste plastics of PP and LDPE in a semibatch reactor under atmospheric pressure, Energy and Fuels, 29 (2015) 2289-2298.

https://pubs.acs.org/doi/10.1021/ef502919f

[53] Ç. Çelikgöğüs, A. Karaduman, Thermal-catalytic Pyrolysis of Polystyrene Waste Foams in a Semi-Batch Reactor, Energy Sources, Part A: Recovery, Utilization, and Environmental Effects, 37 (2015) 2507-2513.

https://www.tandfonline.com/doi/abs/10.1080/15567036.2011.626492

[54] S. C. Cardona, A. Corma, Tertiary recycling of polypropylene by catalytic cracking in a semi-batch stirred reactor: use of spent equilibrium FCC commercial catalyst, Applied Catalysis B: Environmental 25 (2000) 151162. https://doi.org/10.1016/S0926-3373(99)00127-7

[55] H. Gulab, M. R. Jan, J. Shah, G. Manos, Plastic catalytic pyrolysis to fuels as tertiary polymer recycling method: Effect of process conditions, Journal of Environmental Science and Health Part A 45 (2010) 908-915.

https://www.tandfonline.com/doi/abs/10.1080/10934521003709206

[56] A. R. Songip, T. Masuda, H. Kuwahara, K. Hashimoto, Kinetic studies for catalytic cracking of heavy oil from waste plastics over REY zeolite Energy and Fuels 8 (1994) 131-135.

https://pubs.acs.org/doi/abs/10.1021/ef00043a022

[57] M. A. Uddin, K. Koizumi, K. Murata, Y. Sakata, Thermal and catalytic degradation of structurally different types of polyethylene into fuel oil, Polymer degradation and stability 56 (1997) 37-44.

https://doi.org/10.1016/S0141-3910(96)00191-7

[58] J. M. Arandes, I. Abajo, D. Lopez-Valerio, I. Fernandez, M. J. Azkoiti, M. Olazar, J. Bilbao, Transformation of several plastic wastes into fuels by catalytic cracking, Industrial and Engineering Chemistry Research 36 (1997) 4523-4529. https://pubs.acs.org/doi/full/10.1021/ie970096e

[59] S. H. Ng, H. Seoud, M. Stanciulescu, Y. Sugimoto, Conversion of polyethylene to transportation fuels through pyrolysis and catalytic cracking, Energy and Fuels 9 (1995) 735-742.

https://pubs.acs.org/doi/abs/10.1021/ef00053a002

[60] M. del R. Hernández, A. Gómez, Á.N. García, J. Agulló, A. Marcilla, Effect of the temperature in the nature and extension of the primary and secondary reactions in the thermal and HZSM-5 catalytic pyrolysis of HDPE, Applied Catalysis A: General 317 (2007) 183-194. https://doi.org/10.1016/j.apcata.2006.10.017

[61] H. Ohkita, R. Nishiyama, Y. Tochihara, T. Mizushima, N. Kakuta, Y. Morioka, A. Ueno, Y. Namiki, S. Tanifuji, Acid properties of silica-alumina catalysts and catalytic degradation of polyethylene, Industrial and Engineering Chemistry Research 32 (1993) 3112-3116. https://pubs.acs.org/doi/abs/10.1021/ie00024a021

[62] R. Van Grieken, D. P. Serrano, J. Aguado, R. Garcia, C. Rojo, Thermal and catalytic cracking of polyethylene under mild conditions, Journal of Analytical and Applied Pyrolysis 58 (2001) 127-142.

https://doi.org/10.1016/S0165-2370(00)00145-5

[63] J. Aguado, J. L. Sotelo, D. P. Serrano, J. A. Calles, J. M. Escola, Catalytic Conversion of Polyolefins into Liquid Fuels over MCM-41: Comparison with ZSM-5 and Amorphous $\mathrm{SiO}_{2}-\mathrm{Al}_{2} \mathrm{O}_{3}$, Energy and fuels 11 (1997) 12251231. https://pubs.acs.org/doi/10.1021/ef970055v 
[64] J. K. Jeon, Y. K. Park, Pyrolysis of an LDPE-LLDPE-EVA copolymer mixture over various mesoporous catalysts, Korean Journal of Chemical Engineering 29 (2012) 196-200. https://doi.org/10.1007/s11814-0110190-6

[65] S. J. Choi, Y. K. Park, K. E. Jeong, T. W. Kim, H. J. Chae, S. H. Park, J. K. Jeon, S. S. Kim, Catalytic degradation of polyethylene over SBA-16, Korean Journal of Chemical Engineering 27 (2010) 1446-1451.

https://doi.org/10.1007/s11814-010-0281-9

[66] J. Y. Lee, S. M. Park, S. K. Saha, S. J. Cho, G. Seo, Liquid-phase degradation of polyethylene (PE) over MFI zeolites with mesopores: Effects of the structure of PE and the characteristics of mesopores, Applied Catalysis B: Environmental 108 (2011) 61-71. https://doi.org/10.1016/i.apcatb.2011.08.009

[67] A. Marcilla, A. Gómez-Siurana, J. G. Quesada, D. Berenguer, Characterization of high-impact polystyrene by catalytic pyrolysis over Al-MCM-41: Study of the influence of the contact between polymer and catalyst, $\begin{array}{llllll}\text { Polymer Degradation } & \text { and } & \text { 1867-1872. }\end{array}$ https://doi.org/10.1016/j.polymdegradstab.2007.06.016

[68] Y. Sakata, M. A. Uddin, A. Muto, Degradation of polyethylene and polypropylene into fuel oil by using solid acid and non-acid catalysts, Journal of Analytical and Applied Pyrolysis 51 (1999) 135-155.

https://doi.org/10.1016/S0165-2370(99)00013-3

[69] A. Marcilla, M. del R. Hernández, Á. N. García, Study of the polymer-catalyst contact effectivity and the heating rate influence on the HDPE pyrolysis, Journal of Analytical and Applied Pyrolysis 79 (2007) 424-432. https://doi.org/10.1016/i.jaap.2006.10.017

[70] V. P. Caldeira, A. G. Santos, D. S., Oliveira, R. B. Lima, L. D. Souza, S. B. Pergher, Polyethylene catalytic cracking by thermogravimetric analysis, Journal of Thermal Analysis and Calorimetry 130 (2017) 1939-1951 https://doi.org/10.1007/s10973-017-6551-6

[71] C. H. Collett, J. McGregor, Things go better with coke: the beneficial role of carbonaceous deposits in heterogeneous catalysis, Catalysis Science and Technology 6 (2016) 363-378.

DOI: $10.1039 /$ C5CY01236H https://pubs.rsc.org/en/content/articlepdf/2016/cy/c5cy01236h

[72] M. Guisnet, P. Magnoux, Coking and deactivation of zeolites: influence of the pore structure, Applied Catalysis 54 (1989) 1-27. https://doi.org/10.1016/S0166-9834(00)82350-7

[73] S. Chen, G. Manos, In situ thermogravimetric study of coke formation during catalytic cracking of normal hexane and 1-hexene over ultrastable Y zeolite, Journal of Catalysis 226 (2004) 343-350.

https://doi.org/10.1016/i.jcat.2004.06.004

[74] G. Elordi, M. Olazar, G. Lopez, M. Amutio, M. Artetxe, R. Aguado, J. Bilbao, Catalytic pyrolysis of HDPE in continuous mode over zeolite catalysts in a conical spouted bed reactor, Journal of Analytical and Applied Pyrolysis 85 (2009) 345-351. https://doi.org/10.1016/i.jaap.2008.10.015 